\title{
RECEITA PARA SE TORNAR UM "TRANSEXUAL \\ VERDADEIRO": DISCURSO, INTERAÇÃO E (DES) \\ IDENTIFICAÇÃO NO PROCESSO TRANSEXUALIZADOR
}

\section{RECIPE TO BECOME A "TRUE TRANSSEXUAL": DISCOURSE, INTERACTION AND (DIS)IDENTIFICATION AT A GENDER IDENTITY CLINIC}

\section{Rodrigo Borba*}

\section{RESUMO}

Com base em uma abordagem foucaultiana à análise do discurso e uma análise interacional de inspiração goffmaniana, este artigo investiga as micro-dinâmicas pelas quais sistemas de conhecimento que patologizam a transexualidade como uma enfermidade mental são incorporados nas ações de profissionais de saúde e usuários/as transexuais do Sistema Único de Saúde. A partir de um trabalho de campo etnográfico de 13 meses, investiga-se um dos serviços de referência no Processo Transexualizador no SUS. O artigo discute como esses discursos biomédicos disponibilizam recursos semióticos para a identificação de "transexuais verdadeiros", solidificando um modelo metapragmático de identidade. A análise focaliza trajetórias de socialização (WORTHAM, 2006) durante as quais uma usuária nova da clínica paulatinamente aprendeu a entextualizar (SILVERSTEIN E URBAN, 1996) o modelo do "transexual verdadeiro", tornando-se, assim, um corpo dócil (FOUCAULT, 1975/2011) para os propósitos do Processo Transexualizador. Esse aprendizado se deu intertextualmente pela organização sequencial de turnos-defala e, sobretudo, no par pergunta-resposta através dos quais a psicóloga oferece a sua interlocutora os itens semióticos para a construção de uma performance que satisfaça as demandas diagnósticas do cuidado em saúde trans-específico.

Palavras-chave: análise do discurso; cuidado à saúde; análise interacional; trajetórias de socialização; despatologização

\section{ABSTRACT}

Grounded in a Foucauldian genealogical approach to discourse analysis and in Goffmanianinspired interactional analysis, this paper investigates how knowledge systems that pathologize transsexuality as a mental disorder get gradually embodied in consultations at a Brazilian gender identity clinic. The research draws upon 13-month ethnographic fieldwork at one of the Brazilian gender clinics. It analyses how biomedical discourses make available semiotic resources for the identification of "true transsexuals", solidifying, thus, a metapragmatic model of identity. The analyses focus on socialization trajectories (WORTHAM, 2006) during which a new transsexual client of the clinic gradually learned

\footnotetext{
*Universidade Federal do Rio de Janeiro, Rio de Janeiro, Brasil. rodrigoborba@letras.ufri.br
} http://dx.doi.org/10.1590/010318135029178631 
how to entextualize (SILVERSTEIN AND URBAN, 1996) the identity model of "true transsexual" and, thus, gradually became a docile body for the purposes of the clinic. This learning dynamics took place in the sequential organization of turns-at-talk and, above all, in the question-answer adjacency pair in which a psychologist offered her interlocutor semiotic items for the construction of a performance that fulfills the requirements of the Brazilian trans-specific healthcare program.

Keywords: discourse analysis; healthcare; interactional analysis; socialization trajectories; depathologization

\section{INTRODUÇÃO}

No Sistema Único de Saúde (SUS, doravante), para que uma pessoa transexual tenha seu cuidado à saúde integral garantido ela necessita receber um diagnóstico psiquiátrico para que as cirurgias de redesignação sexual e a terapia hormonal sejam oferecidas gratuitamente pelo Estado. Neste artigo, uso o termo "pessoas transexuais" (e suas variantes, sujeitos e indivíduos transexuais) em referência ao grupo de indivíduos que, grosso modo, se identificam com o gênero oposto àquele designado no nascimento e baseado na morfologia do sexo congênito. $\mathrm{O}$ termo visa ser inclusivo ao agregar mulheres transexuais e homens transexuais em suas variadas e contingentes relações com o gênero. Com isso, também se evita a essencialização da experiência implicada no uso de "transexual" como substantivo genérico. Vivenciar alguma forma de transexualidade é uma das qualidades desses indivíduos. Nesse sentido, a transfeminista Gomes de Jesus (2012:15) pontua que o uso do termo isoladamente "soa ofensivo", pois reduz a complexidade da experiência. Nessa mesma linha, utilizo o termo "mulheres transexuais" para me referir a pessoas transexuais que fazem a transição homempara-mulher e "homens transexuais" para designar transição mulher-para-homem. Dessa forma, evidencia-se o gênero construído e não o sexo congênito dos indivíduos, como é corriqueiro em instâncias médicas (BENTO, 2006).

O diagnóstico exigido pelas normativas que regem o Processo Transexualizador no SUS é baseado nos critérios avaliativos preconizados pela Organização Mundial de Saúde em seu Código Internacional de Doenças e Problemas Relacionados à Saúde (CID) e pela Associação Americana de Psiquiatria em seu Manual Diagnóstico e Estatístico de Doenças Mentais (DSM). Em ambos os documentos, a transexualidade é categorizada como uma patologia psiquiátrica: no CID-10 ela é classificada como um transtorno da personalidade e do comportamento adulto; no DSM-IV a encontramos no capítulo sobre transtornos da identidade sexual onde está elencada como um transtorno da 
identidade de gênero. ${ }^{1}$ Ecos dessas posições epistemológicas são encontradas na documentação brasileira que regula o Processo Transexualizador, nomeadamente a Portaria 1.707/2008 do Ministério da Saúde, que institui o processo no SUS, e as Resoluções 1.652/2002 e 1.955/2010 do Conselho Federal de Medicina, que regulamentam o cuidado em saúde trans-específico oferecido no país. Tais documentos impõem a obrigatoriedade de acompanhamento psiquiátrico por dois anos durante os quais um/a profissional de saúde mental deve avaliar, seguindo o CID e o DSM, se a pessoa que requer acesso à terapia hormonal e/ou às cirurgias de redesignação sexual é, de facto, um "transexual verdadeiro". ${ }^{2}$

Nesse contexto, a necessidade de um diagnóstico psiquiátrico impõe tensões interacionais (STONE, 1991/2007; NEWMAN, 2000; BUTLER, 2004; BENTO, 2006; TEIXEIRA，2013; BORBA，2016; 2014A; 2014B). Segundo Louise Newman (2000:400), para exemplo, "para o/a profissional de saúde mental a tarefa é distinguir o/a 'verdadeiro/a transexual' (ou transexual primário) de outros/as com graus menores de disforia de gênero ou com outros problemas de gênero para os quais a cirurgia não é considerada um tratamento apropriado." Assim, durante o tempo de acompanhamento pré-cirúrgico, de acordo com essa autora, o/a profissional de saúde deve elaborar um diagnóstico "preciso" sobre a "desordem" de identidade de gênero do/a "paciente" através de aconselhamento individual. Por sua vez, os indivíduos transexuais devem convencer a equipe desses programas de que satisfazem todos os quesitos necessários para ter sua cirurgia aprovada, reatualizando, portanto, os sistemas de conhecimento científico que os patologizam. A exigência de um diagnóstico, dessa forma, gera tensões interacionais que devem ser administradas localmente em virtude da malha de significados que rege o Processo Transexualizador. Nesse cenário, ainda segundo Newman, a pergunta que guia as ações do/a profissional de saúde é: "como posso ter certeza

1 Em 2012 foi publicado o DSM-V, versão atual do documento, onde a transexualidade é classificada como disforia de gênero. Em psiquiatria, disforia seria o antônimo de euforia, condição na qual o indivíduo apresenta uma tristeza psiquicamente debilitante. Embora o DSM-V apresente uma nova nomenclatura para a condição, os critérios diagnósticos sofreram poucas alterações. Vale lembrar ainda que apesar de atualmente o DSM-V estar em vigor, utilizo como texto de referência e análise o DSM-IV, sua versão anterior, já que este vigorava durante o trabalho de campo realizado entre 2009 e 2010 no Programa de Atenção Integral à Saúde Transexual.

2 Utilizo o termo "transexual verdadeiro" entre aspas e sempre no masculino como forma de enfatizar sua origem nos sistemas de saber que produzem a transexualidade como transtorno mental. Nesse sentido, o uso do conceito com essa configuração pretende sublinhar seu caráter de diagnóstico baseado em idealizações sobre o que constitui uma transexualidade supostamente autêntica. Além disso, o uso das aspas pretende enfatizar o descompasso entre esse conceito e as diferentes formas que pessoas transexuais experienciam suas corporalidades e subjetividades em suas vidas diárias, o que ficará claro no decorrer do argumento aqui desenvolvido. 
que esse paciente é um/a transexual e não está dizendo o que acha que quero ouvir para obter tratamento?". Pessoas transexuais, por sua vez, se pautam pela pergunta: "como posso convencer esse médico de que sou um/a transexual para ter direito à cirurgia?" Nessa dinâmica, preocupadas em ter sua participação no programa negada, pessoas transexuais rapidamente aprendem "a história de vida necessária para passar por transexuais com sucesso" (HIRD, 2002:583).

Embora o aprendizado dessa narrativa de "transexual verdadeiro" tenha sido observado por outros/as pesquisadores/as preocupados/as em apontar a pouca ressonância que os critérios diagnósticos têm na vida e nas subjetividades de pessoas transexuais (BUTLER, 2004; BENTO, 2006; STONE, 1991/2007; TEIXEIRA, 2013), essas análises são baseadas em relatos retrospectivos de pessoas transexuais em entrevistas etnográficas. Portanto, sabe-se pouco sobre a materialização interacional desse discurso em consultório. Sabe-se menos ainda sobre o processo de aprendizado dessa narrativa e sobre as dinâmicas de desidentificação de formas "mundanas" de vivenciar a transexualidade que ela movimenta. ${ }^{3}$ Nesse cenário, este artigo objetiva entender os fenômenos micro-interacionais que possibilitam a materialização de uma linguagem diagnosticamente adequada para os propósitos do Processo Transexualizador e, a partir disso, discute os processos de assujeitamento e desidentificação que a exigência de um diagnóstico psiquiátrico engendra. Pergunta-se: como um indivíduo se torna um sujeito (transexual) legítimo para os propósitos institucionais do cuidado à saúde trans-específico brasileiro?

Para o enfrentamento dessa questão, a pesquisa relatada aqui foi baseada em um trabalho de campo de cunho etnográfico de 13 meses no Programa de Atenção Integral à Saúde Transexual (PAIST, doravante) ${ }^{4}$ Durante o trabalho de campo, o PAIST contava com três profissionais de saúde principais: um cirurgião, uma psicóloga e um psiquiatra. Além desses, havia também dois médicos visitantes (fellows) que buscavam sua especialização em cirurgias urológicas. À época, o serviço

3 A analista da conversa Susan Speer $(2009 ; 2010 ; 2011)$ investigou interações entre psiquiatras e clientes transexuais de uma clínica em Londres. Contudo, sua filiação a uma compreensão de contexto como co-texto (BILLIG, 1999) e seu foco restrito ao que os/as participantes explicitamente se orientam impelem a pesquisadora a tomar o status da transexualidade como doença mental por garantido. Como tal, as análises de Speer ignoram a centralidade de discursos patologizantes para as interações que ela investiga.

4 Por motivos de caráter ético, pseudônimos são utilizados. O projeto mais abrangente do qual esta pesquisa faz parte, intitulado "Redescrições da transexualidade: interação, identidade e acesso a Programas de Redesignação Sexual", seguindo a Resolução 196/96 do Conselho Nacional de Saúde sobre ética em pesquisa com seres humanos, foi submetido ao Comitê de Ética e Pesquisa (CEP) do hospital onde o PAIST está inserido e foi devidamente aprovado (processo número CAAE 0040.0.228.000-10). Devido a restrições colocadas pelo CEP, os dados foram gravados somente em áudio. 
atendia 129 usuários/as transexuais. Mais detalhes sobre a metodologia e o corpus gerado podem ser encontrados em Autor (2014a). Para os propósitos deste artigo, analisa-se um corpus de 5 consultas entre Verônica, uma nova usuária do PAIST, e Inês, a psicóloga. Verônica teve sua primeira consulta em fevereiro de 2010 e, nos meses seguintes, muitos outros encontros entre as duas aconteceram ( 5 deles foram gravados e transcritos). Nessas consultas, o foco terapêutico de Inês recaiu no descompasso flagrante entre as narrativas de vida e a apresentação corporal de Verônica, por um lado, e o modelo diagnóstico de "transexual verdadeiro", por outro. Argumenta-se que essa série de consultas constitui uma trajetória de socialização (WORTHAM, 2006), i.e., um complexo de eventos comunicativos ligados no tempo, durante a qual um indivíduo se torna um tipo institucionalmente reconhecível de sujeito (trans). Com o intuito de traçar os fenômenos interacionais que movimentam essa trajetória de (des)identificação, a discussão é guiada por uma abordagem foucaultiana de análise do discurso e por análises interacionais à la Goffman, cuja a ligação é discutida na seção seguinte.

\section{DISCURSO, INTERAÇÃO E A PRODUÇÃO DE SUJEITOS DÓCEIS}

Em seus trabalhos, Foucault delineia uma mudança histórica que marcou a transição da soberania para o que o filósofo chama de sociedades disciplinares: da identificação das pessoas com base em seus comportamentos "naturais" para sua classificação e disciplinarização de acordo com suas disposições mentais e espirituais (FOUCAULT, 1976/2003; 1975/2011). Nesse contexto, o filósofo explica como a produção de saberes nas ciências sociais e o desenvolvimento de categorias científicas simultaneamente possibilitaram novas formas de conhecimento e novas formas de exercício de poder. Um dos traços centrais dessa mudança envolve a proliferação de taxonomias e práticas de classificação de pessoas em instituições como o hospital (FOUCAULT, 1979/2013b) e a prisão (FOUCAULT, 1975/2011).

A burocratização dessas taxonomias possibilitou que governos e suas instituições pudessem conhecer esses indivíduos e prever/prescrever como eles se comportariam em formas que eram indisponíveis antes do interesse das ciências por suas vidas. Consoante Foucault, assim, os novos sistemas de classificação permitiram a identificação de certos indivíduos como determinados tipos de sujeitos e a elaboração de técnicas institucionais de vigilância e controle. Em outros termos, produziram-se técnicas de governo dos outros (FOUCAULT, 2009) que acabariam por movimentar práticas de autovigilância e subjetivação (i.e., governo 
de si), fazendo o indivíduo progressivamente, por si mesmo, manter-se nas tramas de saber/poder que o enredam - o que Foucault (1988) chama de técnicas de si. ${ }^{5}$

O filósofo francês traça o surgimento e os efeitos materiais de uma multiplicidade de discursos, que ele define como "práticas que sistematicamente formam os objetos dos quais falam" (FOUCAULT, 2007:55). Nesse sentido, discurso não envolve somente a linguagem em uso. Ele também inclui um complexo de sistemas de conhecimento, categorias científicas, instituições, leis, arquitetura, proposições filosóficas, padrões morais etc. (FOUCAULT, 1979/2013). Tais discursos interlaçam indivíduos em uma rede de sistemas de saber que, postos em funcionamento em instituições, produzem dinâmicas de governamentalidade que acabam por transformá-los em sujeitos. Governamentalidade, um conceito desenvolvido na última fase de sua carreira (FOUCAULT, 1982; 1988; 2009), se refere aos "esforços para moldar, guiar, direcionar a conduta dos outros [...] Práticas de governo são tentativas deliberadas de lapidar o comportamento em certas formas para atingir certos objetivos" (ROSE, 1999:3-5). Governamentalidade seria, então, o efeito mais material dos discursos que Foucault descreve: ao recair sobre o corpo, a subjetividade e o comportamento, ela engendra dinâmicas institucionais pelas quais sujeitos reconhecíveis emergem. Para Foucault, sujeito é um conceito de duas faces: é-se "sujeito ao outro através do controle e da dependência e ligado à sua própria identidade através de uma consciência ou do autoconhecimento" (FOUCAULT, 1988:278). Ambos os sentidos são importantes para entendermos como certas pessoas são transformadas em "transexuais verdadeiros" no SUS, como as análises deixarão claro.

Os documentos que patologizam a transexualidade (i.e., CID, DSM e as Resolusões do CFM) são uma engrenagem na maquinaria discursiva que produz indivíduos cujo gênero designado ao nascimento está em desacordo com suas identificação social como certos tipos de sujeitos doentes. Esses documentos entextualizam (SILVERSTEIN E URBAN, 1996) sistemas de conhecimento biomédico baseados na identificação da patologia, sua etiologia e progressão temporal dentro de uma constelação observável e interpretável de signos e sintomas (FOUCAULT, 1963/2001; CAMARGO JR., 1997). O conceito de entextualização é importante para entendermos como discursos, no sentido foucaultiano, se solidificam em forma de linguagem em uso e constituem padrões institucionais de

\footnotetext{
5 É importante enfatizar que na perspectiva foucaultiana, os dispositivos eles mesmos fornecem as ferramentas para sua própria contestação (ver LIMA, 2014). Nesse sentido, indivíduos podem gestar técnicas de si que contestem, desde dentro, os efeitos assujeitadores dos dispositivos em suas vidas hodiernas.
} 
textualidade que regem as ações de indivíduos na sua vida hodierna. Bauman (2004) explica que

O processo de entextualização, ao circunscrever um trecho de discurso de seu contexto, inserir propriedades coesivas formais e (com frequência, mas não necessariamente) produzir coerência interna serve para objetificá-lo como unidade textual a qual se pode fazer referência e, assim, pode ser descrita, nomeada, mostrada, citada e tratada como um objeto. [...] Um texto, portanto, a partir dessa perspectiva, é discurso descontextualizável (p.4).

Grosso modo, entextualização pode ser entendida como o processo de retirar recursos semióticos de um contexto e materializá-los em nossas ações sociais em outro lugar e tempo. Isso acontece quando um texto (ou extratos de um texto) é (são) retirado(s) de seu contexto de produção primário e trazido(s) para outro, interligado ou distante do original. Assim, um texto cultural entextualizado é um texto descontextualizado e recontextualizado em outra geografia e temporalidade.

No cuidado à saúde trans-específico, a entextualização de discursos patologizantes se materializada na imposição institucional de um diagnóstico psiquiátrico para que o SUS forneça as intervenções corporais gratuitamente. Como discutido anteriormente, o trabalho de Foucault oferece um ferramental poderoso para entendermos como tais sistemas de conhecimento emergiram historicamente. Mas sabe-se pouco sobre como tais discursos acabam por ser corporificados nas ações de usuários/as trans nos consultórios médicos ou sobre seus efeitos sobre as práticas de cuidado à saúde e suas subjetividades. Para tanto, precisa-se de um olhar mais situado para os detalhes do que acontece quando profissionais da saúde e pessoas transexuais interagem. Nesse sentido, uma lente analítica goffmaninana pode ser útil na investigação de como os discursos dos quais nos fala Foucault atingem a vida cotidiana de pessoas de carne e osso.

Se o filósofo francês estava interessado em analisar o surgimento de amplos sistemas de conhecimento, Goffman, por sua vez, procurava entender como pessoas interagem in situ, nas suas vidas diárias e nas instituições das quais fazem parte (ver, por exemplo, GOFFMAN, 1959; 1964/2002; 1974; 1978/2002). Com essa interpretação em perspectiva, pode-se dizer que o trabalho de Foucault é "descendente, direcionado à totalidade de sistemas de conhecimento" (HACKING, 2004:278) enquanto o foco de Goffman é "ascendente - sempre preocupado com indivíduos em lugares específicos, entrando ou recusando relações sociais com outras pessoas" (HACKING, 2004:278). Grande parte das pesquisas sobre transexualidade nas ciências humanas e sociais segue uma perspectiva foucaultiana e, assim, mapeia a emergência dos discursos que patologizam a transexualidade (BENTO, 2006; LIMA, 2011; TEIXEIRA, 2013). Ao lançar seu foco sobre 
como pessoas negociam relações intersubjetivas em suas interações diárias, uma análise interacional à la Goffman pode contribuir para que entendamos como a classificação da transexualidade como um transtorno mental é corporificada nas práticas interacionais de cuidado à saúde do Processo Transexualizador. Como aponta Rampton (2014), a análise dos detalhes do desenvolvimento turno-a-turno de uma interação situada oferece à perspectiva foucaultiana um microscópio, por assim dizer, pois possibilita um olhar mais atento a como o poder capilarmente atinge os indivíduos, toca seus corpos, suas palavras, seus gestos e suas relações com outros.

É nesse sentido que Hacking (2004) e Rampton (2014) defendem que tanto Foucault quanto Goffman são centrais para a investigação de como indivíduos são transformados em sujeitos; juntos, eles fornecem uma entrada analítica nas relações entre as dinâmicas macro-sociológicas e micro-interacionais da governamentalidade. Uma genealogia de discursos foucaultiana possibilita que entendamos como certos indivíduos se tornaram de interesse às ciências e às instituições; uma abordagem interacional ascendente inspirada pelo trabalho de Goffman nos ajuda a estudar como o discurso, no sentido foucaultiano, acaba por ser institucionalizado e incorporado na vida das pessoas. Essas diferentes abordagens de análise do discurso são centrais para que possamos compreender a constituição de sistemas de conhecimento e sua solidificação em técnicas locais de vigilância e punição. Nesse sentido, ambas são úteis para estudar o desenvolvimento de práticas situadas de governo de si e do outro que cumulativamente produzem sujeitos dóceis para os propósitos de certas instituições. Com isso em perspectiva, a seção seguinte discute o dispositivo da transexualidade e a emergência do modelo biomédico de "transexual verdadeiro" que guia as práticas de cuidado à saúde no Processo Transexualizador e movimenta dinâmicas microinteracionais de desidentificação de formais locais, "leigas" de vivenciar a transexualidade.

\section{O DISPOSITIVO DA TRANSEXUALIDADE E A INVENÇÃO DO "TRANSEXUAL VERDADEIRO"}

O dispositivo da transexualidade constitui um amálgama "de saberes [...] relações e práticas de poder, [que] estabelecem sobre os corpos, o sexo e a sexualidade toda uma organização conceitual e prática que [...] legitimou a transexualidade como um fenômeno [...] do âmbito médico, principalmente psiquiátrico" (LIMA, 2011:119). No Brasil, pesquisas em diversas áreas (por 
exemplo, antropologia, sociologia, história, medicina social, entre outras) têm investido na elaboração de uma genealogia desse dispositivo (BENTO, 2006; 2008; ARÁN, 2006; MURTA, 2011; ARÁN, MURTA E LIONÇO, 2009; LIMA, 2011; TEIXEIRA, 2013 entre outros/as). Faz-se importante ressaltar que este artigo não tenta esgotar os fenômenos que constituem o dispositivo da transexualidade devido a sua amplitude e diversidade. De fato, dada a abrangência de estudos sobre este dispositivo em diversas áreas, a discussão que apresento é necessariamente resumida e tem por objetivo (1) familiarizar estudiosos/as da linguagem com este debate e (2) contextualizar esta pesquisa dentro desse campo de saberes/poderes que movimenta a psiquiatrização (MURTA, 2007) das vivências transexuais.

Central para as discussões foucaultianas é o conceito de dispositivo. Consoante o filósofo francês, dispositivos são "um conjunto heterogêneo de práticas discursivas e não discursivas que possuem uma função estratégica de dominação. O poder disciplinar obtém sua eficácia da associação entre discursos teóricos e práticos" (FOUCAULT, 1979/2013:364). Os dispositivos são, assim, a rede que se pode estabelecer entre "discursos, organizações arquitetônicas, decisões regulamentares, leis, medidas administrativas, enunciados científicos, proposições filosóficas, morais, filantrópicas" (FOUCAULT, 1979/2013:364) que capturam indivíduos, assujeitando-os como determinados tipos de sujeitos.

Deleuze (1990) explica que um dispositivo é "um conjunto multilinear, composto por linhas de natureza diferente" (p. 155): a linha de visibilidade (que delimita o que pode ser visto/mostrado e como se deve vê-lo), a linha de enunciação (que produz o que pode ser dito e como dizê-lo e ouvi-lo), a linha de forças (a dimensão do poder, seus embates, resistências e as fissuras que podem produzir no dispositivo) e a linha de subjetivação (que movimenta processos de individualização). O jogo multiforme estabelecido entre essas linhas permitiu a Foucault "criar uma história dos diferentes modos pelos quais os seres humanos [...] se tornam sujeitos" (FOUCAULT, 1982/2010:273).

Com o conceito de dispositivo, portanto, Foucault desvela processos de assujeitamento que produzem determinados tipos de sujeitos por sua cooptação em campos de saberes que, estabelecendo jogos de poderes entre si, configuram sua relação com os outros e consigo. Tais processos instauram e mobilizam uma multiplicidade de "operações nos corpos das pessoas, sobre suas almas, sobre seu próprio pensamento, sobre sua própria conduta" (FOUCAULT, 1993:209), isto é, técnicas de si que colocam um corpo e uma subjetividade sob as tramas de saberes/poderes que compõem um dispositivo. Estas técnicas de si envolvem um processo de autoformação fomentado por uma figura de autoridade (médico, 
padre, psicanalista...) que catalisa os elementos heterogêneos do dispositivo e os projeta no outro (RABINOW, 2002), movimentando, assim, processos multiformes de assujeitamento e resistência. Vale ressaltar, contudo, que assujeitamentos não acontecem de forma pacífica. Já que "lá onde há poder, há resistência" (FOUCAULT, 1976/2003:91), constituir-se como indivíduo nas tramas dos dispositivos nos quais agimos implica uma relação dialógica com as normas e os regimes de verdade que os sustentam. Nas linhas de força do dispositivo, emaranham-se práticas de controle e possibilidades de resistências para as quais o próprio dispositivo fornece os instrumentos.

De acordo com Bento (2006), a categorização científica da transexualidade seguiu duas vertentes principais: uma biologista, que entendia o "transtorno" como residindo na estrutura biológica do corpo e defensora das cirurgias de transgenitalização, e outra psicanalítica, que considerava o papel da socialização primária na constituição da identidade de gênero e entendia a transexualidade como um desvio da socialização "correta", sendo assim contra a banalização das cirurgias de transição. Nesse campo de conflito entre saberes, duas figuras são centrais na definição da transexualidade como um transtorno psiquiátrico e na classificação de "transexuais verdadeiros": o endocrinologista Harry Benjamin (1966/1999) e o psicanalista Robert Stoller (1975/1982). Embora contraditórias entre si no que tange à gênese e a administração clínica de pessoas transexuais, as teorias de Benjamin e Stoller são reentextualizadas (SILVERSTEIN E URBAN, 1996) nos critérios diagnósticos do DSM e do CID. Tais documentos moldam o manuseio clínico de usuários/as do Processo Transexualizador no SUS, solidificando, assim, recursos semióticos que indexicalizam uma transexualidade "autêntica" e servindo de arcabouço diagnóstico para identificação do "transexual verdadeiro", conceito cunhado por Benjamin em seu livro O fenômeno transexual (1966/1999). O "transexual verdadeiro", em Benjamin, seria invertido, ansioso, assexuado e, paradoxalmente, heterossexual. Em outras palavras, ele

1) vive uma inversão psicossocial total; 2 ) pode viver e trabalhar como uma mulher, mas apenas vestir as roupas não lhe dá alívio suficiente; 3 ) intenso mal-estar de gênero; 4) deseja intensamente manter relações com homens e mulheres normais; 5) solicita a cirurgia com urgência; 6) odeia seus órgãos genitais (BENJAMIN, 1966/1999:45).

Ao propor uma lista de características que distinguiriam os/as "transexuais verdadeiros/as" de pessoas com um menor nível do suposto transtorno de identidade de gênero, o livro de Benjamin, assim como qualquer discurso científico, não só descreve um dado "problema", mas produz o objeto sobre o qual fala (MARTínEZGUZMÁN E ÍNIIGUEZ-RUEDA, 2010). Dessa forma, a obra do endocrinologista 
se apresenta como um mecanismo performativo que servirá de guia na produção dos critérios diagnósticos preconizados pelo DSM e pelo CID.

Stoller (1975/1982), em contrapartida, focalizou seus esforços na análise dos processos de socialização que supostamente levariam, na vida adulta, a uma identidade de gênero adequada ao sexo atribuído. Para tanto, o psicanalista trabalhou com meninos cujos pais consideravam "efeminados". Em seu livro A experiência transexual, Stoller propõe que a origem de comportamentos inadequados de gênero nas crianças (que poderiam motivar o desejo de se submeter às cirurgias de redesignação sexual no futuro) é produto de dinâmicas psicossociais traumáticas impostas pela relação disfuncional com seus pais, especialmente a mãe. Seguindo os ensinamentos de Freud e seu conceito de complexo de castração, Stoller caracteriza a mãe do "transexual verdadeiro" como extremamente invejosa dos homens; essa inveja expressaria seu desejo inconsciente de ser homem. Pessoas transexuais, para Stoller, nasceriam da soma da equação: pai ausente + mãe dominadora. Nesse sentido, as cirurgias, para este psicanalista, deveriam ser evitadas. Sua tarefa como psicólogo, defende Stoller, era devolver às crianças que atendia o sentido de pertencimento ao seu sexo natal por meio da estratégia clínica que denomina de "complexo de Édipo terapeuticamente induzido" (STOLLER, 1975/1982:101).

As teorias de Benjamin e Stoller (apresentadas de forma muito resumida acima) são solidificadas como texto no DSM e no CID e seus critérios diagnósticos para o Transtorno de Identidade de Gênero. Não tenho espaço aqui para discutir esses critérios de forma detalhada, mas vale ressaltar alguns deles: descoberta da transexualidade numa tenra idade, ojeriza pelos órgãos genitais, estilística e práticas corporais estereotipadas, heterossexualidade (e assexualidade), desejo inabalável pelas cirurgias de transgenitalização, tendência à depressão e ao suicídio. É importante enfatizar, contudo, que esses critérios diagnósticos são recuperados nos documentos do Conselho Federal de Medicina e do Ministério da Saúde que regulamentam o Processo Transexualizador para os quais "o paciente transexual [é] portador de desvio psicológico permanente de identidade sexual, com rejeição do fenótipo e tendência à automutilação e/ou autoextermínio" (BRASIL, 2010:110, grifos meus). Nesse sentido, a coadunação desses saberes em critérios diagnósticos produziu um modelo metapragmático de identidade (WORTHAM, 2006) que estabelece as condições de visibilidade (o que/como mostrar e como ver) e de dizibilidade (o que/como dizer e como ouvir) para que se seja diagnosticado como "transexual verdadeiro".

Um modelo metapragmático de identidade é "um modelo de tipos reconhecíveis de pessoas (e.g. alunos/as inadequadamente resistentes) que 
participam de tipos reconhecíveis de interação (e.g. recusa de colaborar com a aula)" (WORTHAM, 2006:32). No nível analítico, signos linguísticos utilizados na interação situada (cf. Goffman) só podem fazer sentido quando, em amálgama, indexicalmente apontam para a história de discursos (cf. Foucault) que produz o arcabouço de sentidos para entender o modelo metapragmático em ação. Consoante Wortham (2006), não se deve ver as relações entre signos linguísticos e modelos de identidade como estáticas e a-históricas. A breve genealogia dos discursos sobre transexualidade feita aqui considera como o modelo de "transexual verdadeiro" emergiu a partir de constelações de saber/poder dentro de campos de conhecimento médico. Tal construção discursiva estabeleceu os campos de ação que "transexuais verdadeiros" podem se engajar, i.e., eles devem desejar se submeter às cirurgias, odiar seus órgãos genitais e contar narrativas do tipo "sou um homem/uma mulher no corpo equivocado". Essa história de uso constrange o efeito do signo linguístico localmente. Assim, "o modelo metapragmático 'regimenta' o signo (i.e., deixa claro que aspectos do contexto são relevantes para interpretá-lo) a partir de vários aspectos contextuais que podem ser relevantes. Essa regimentação [...] limita os possíveis significados do signo, deixando claro como as pessoas devem interpretá-lo ou reagir a ele" (WORTHAM, 2006:33). Nesse sentido, transformarse num tipo reconhecível de sujeito implica a contextualização situada de um signo dentro de campos semânticos que extrapolam seu uso local.

Como esses discursos sobre o "transexual verdadeiro" são corporificados no Processo Transexualizador? Quais são seus efeitos nas performances identitárias de usuários/as trans e na linguagem que eles/as usam? Como, afinal, um indivíduo acaba por ser transformado em um tipo reconhecível de sujeito (trans) para os propósitos do Processo Transexualizador? A história interacional de Verônica e Inês fornece subsídios para que entendamos como esses discursos patologizantes são gradual e insidiosamente incorporados à interação local na produção de um "transexual verdadeiro".

\section{SOBRE COMO UM INDIVÍDUO SE TORNA SUJEITO: INTERAÇÃO E DISCURSO, PRAGMÁTICA E METAPRAGMÁTICA - GOFFMAN E FOUCAULT}

A seção anterior traçou as linhas de força, visibilidade e dizibilidade que forjaram o "transexual verdadeiro" como um modelo metapragmático de identidade. Esta seção investiga como esses discursos (no sentido foucaultiano) se materializam em uma série interconectada de interações entre Verônica, uma nova usuária do 
PAIST, e Inês, a psicóloga do programa. Minhas notas de campo indicam que entre fevereiro e junho de 2010, Verônica e Inês se encontraram pelo menos 10 vezes. Cinco dessas consultas foram gravadas em áudio. Essa série de consultas possibilita que se trace analiticamente os micro-detalhes da trajetória interacional durante a qual a usuária trans gradualmente incorporou em suas performances linguísticas o campo de dizibilidade que limita o que e como um "transexual verdadeiro" pode falar.

A análise dessa trajetória de desidentificação a seguir discute o papel do par adjacente pergunta-resposta, dada sua centralidade na comunicação entre profissionais de saúde e pacientes (HERITAGE, 2010). Analistas da conversa definem o par adjacente como uma sequência de dois turnos de fala, produzidos por falantes diferentes, na qual o primeiro estabelece uma gama de possíveis ações para segui-lo (SCHEGLOFF, 1968; POMERANTZ, 1984; LAU E OSTERMANN, 2005), i.e., perguntas projetam respostas, um convite produz um aceite ou uma recusa, etc. Como as análises que seguem deixarão claro, o par adjacente é um contexto, talvez o mais micro disponível, para o desenvolvimento de dinâmicas de governo, pois, como explica Foucault (1982), "governar [...] é estruturar o possível campo de ação dos outros" (p. 221). Nesse sentido, Rampton (2014) defende que o par adjacente fornece uma perspectiva analítica para investigarmos a "capilaridade micro-física do poder" (FOUCAULT, 1979/2013). De modo mais específico, as análises que seguem investigam as posições discursivas (KENDAL, 2008) produzidas pelas perguntas feitas por Inês e seus efeitos estruturantes para as ações de Verônica. Tais efeitos só podem ser estudados como o resultado de uma série de conexões intertextuais que ligam cada uma das consultas no tempo. Para que se possa dar uma explicação detalhada dos processos interacionais que comparecem na transformação de Verônica num sujeito (trans) legítimo para o PAIST, as análises, a seguir, focalizam como esse aprendizado se dá em momentos chave das várias consultas entre ela e sua psicóloga, o que exige uma discussão textualmente longa.

Em 24 de fevereiro de 2010, Verônica teve sua primeira consulta com Inês (de fato, sua primeira consulta no PAIST). A psicóloga ficara responsável pela gravação e, por vezes, esquecia-se de ligar o aparelho no início da consulta. Isso aconteceu com a interação analisada abaixo. Inês ligou o gravador depois de a consulta ter se iniciado e, assim, não tenho acesso à abertura da interação. $\mathrm{O}$ excerto abaixo inclui o momento em que o gravador foi ligado, durante o qual Inês adota, em suas perguntas, posições discursivas de diagnosticadora, de psicoterapeuta e de professora/avaliadora. ${ }^{6}$

6 As convenções de transcrição se encontram no anexo. 


\section{Excerto 1}

\begin{tabular}{|c|c|c|}
\hline 1 & Inês: & Verônica $>$ vô pedi pra você $<$ me falá- me \\
\hline 2 & & explicá qual é a diferença entre transexual \\
\hline 3 & & $<$ e travesti $>\downarrow$ \\
\hline 4 & & $(4.2)$ \\
\hline 5 & Verônica: & º̂:: como é ${ }^{\circ}$ que vô explicá isso, \\
\hline 6 & Inês: & $>$ não precisa- $<\uparrow$ fala com seu coração Verônica \\
\hline 7 & Verônica: & que que eu a::cho? \\
\hline 8 & & $()$. \\
\hline 9 & Verônica: & ah eu acho que $\uparrow$ são::- são pessoas diferentes \\
\hline 10 & & que tem a- pensa da maneira diferente né $=$ \\
\hline 11 & Inês: & $=>$ exatamente $<\underline{\text { sentem diferente }=}$ \\
\hline 12 & Verônica: & =é. [se sentem-] \\
\hline 13 & Inês: & [tem a $<$ sexua]lidade $>[$ diferen- $]$ \\
\hline 14 & Verônica: & [diferen] te uma da \\
\hline 15 & & outra $=$ \\
\hline 16 & Inês: & $=\mathrm{i}:::$ sso mesmo $\downarrow$ esses suas- $>$ seus amigos $<$ \\
\hline 17 & & que dizem que não querem:: tê::: é:::- que \\
\hline 18 & & que é? é::- são- é- > são o que? < \\
\hline 19 & Verônica: & são travestis $=$ \\
\hline 20 & Inês: & $=$ são traves $[\mathrm{ti}]$ \\
\hline 21 & Verônica: & [são] \\
\hline 22 & & (.) \\
\hline 23 & Inês: & $\mathrm{i}:: \mathrm{s}[\mathrm{so}$ se- $]$ \\
\hline 24 & Verônica: & [maiori]a travesti $\downarrow$ \\
\hline 25 & & $(0.3)$ \\
\hline 26 & Inês: & pois é. \\
\hline 27 & & (.) \\
\hline 28 & Inês: & $<$ o transexual $>$ ele- na grande maioria ele \\
\hline 29 & & $\underline{\text { não }}$ tem relação (sexual) ${ }^{\circ} \mathrm{Com}$ pênis ${ }^{\circ}$ \\
\hline 30 & & $(0.7)$ \\
\hline 31 & Inês: & entendeu? $=$ \\
\hline 32 & Verônica: & $=$ uhum \\
\hline 33 & Inês: & já o travesti não $\downarrow$ eles são- tanto eles são \\
\hline 34 & & ativos quanto eles são [passivos] \\
\hline 35 & Verônica: & [passivo] isso eu sei, \\
\hline 36 & & [são os dois] \\
\hline 37 & Inês: & [então eles] U::sam o pênis, \\
\hline
\end{tabular}




$\begin{array}{lll}38 & \text { Verônica: } & \begin{array}{l}\text { uhum } \\ (0.6)\end{array} \\ 39 & & >\text { entendeu }<\text { a diferença? } \\ 40 & \text { Inês: } & { }^{\circ} \text { enten } \mathrm{di}^{\circ}=\end{array}$

Com a pergunta que lançou na linha 1, Inês estrutura sua relação com a usuária de forma a se colocar em uma posição discursiva em que seu grau de acesso epistêmico ao fato sobre o qual requer informações é menor do que o da usuária. Em outras palavras, com essa pergunta Inês se constrói como não possuindo conhecimento sobre o que questiona e, assim, indica que sua interlocutora é quem detém as informações necessárias para sanar sua falta de informação sobre a diferença entre pessoas transexuais e travestis. Entretanto, sua função institucional como psicóloga de um programa de transgenitalização contradiz essa posição discursiva e, talvez, o lapso de tempo até a usuária tomar o turno para responder (linha 4) indique que ao invés de a pergunta estar legitimamente endereçando um fato desconhecido sobre o qual Verônica sabe mais que a psicóloga, está, ao contrário, testando o conhecimento da usuária - uma pergunta-teste, de facto. Com essa interpretação em tela, podemos considerar essa pergunta como o que analistas da conversa têm chamado de "pergunta de informação conhecida" (MEHAN, 1979; GARCEZ, 2006; KOSHIK, 2010), comumente utilizada por professores/as em salas de aula convencionais ou, nos termos de Fabrício (2007), pan-ópticas. Nesse contexto, o/a professor/a tem o poder de reproduzir conhecimentos e testá-los com questões para as quais já tem uma agenda previamente estabelecida e que lhe outorga o poder de corrigir as respostas que considera erradas, impingindo, assim, à interação professor/ a-aluno/a um caráter de pan-optismo disciplinar. Segundo Fabrício (2007), esse tipo de pergunta funciona como um dispositivo de controle no qual "são gestados [...] regulados e transformados os sujeitos da educação e suas relações consigo mesmos, com os outros e com os conhecimentos" (FABRíCIO, 2007:127).

O lançamento dessa pergunta coloca Verônica numa posição difícil, como indicado pela iniciação de reparo (SCHEGLOFF, JEFFERSON E SACKS, 1977) elaborada pela usuária no turno da linha 5 ( ô: : como é que vô explicá isso $)^{7}$. Percebendo a dificuldade de sua interlocutora satisfazer a agenda imposta

7 No jargão da Análise da Conversa, "reparo e correção são semelhantes, mas não são sinônimos. Correção é [...] entendida como a substituição de um item considerado "errado" por outro considerado "certo", independentemente de ter havido ou não uma interrupção na sequência das ações para a oferta de substituição de um item por outro. Já o reparo se caracteriza sobretudo pela identificação de um problema e por alguma (tentativa de) resolução do mesmo" (LODER, 2008:97). 
por sua pergunta, Inês lança um enunciado típico de consultas psicoterapêuticas: †fala com seu coração Verônica (linha 6). Consoante Vehvilainen (2011), turnos que incitam interlocutores/as a falarem livremente, "do seu coração", sem constrangimentos por percepções de certo e errado, são sequencialmente inseridos em contextos nos quais terapeutas enfrentam resistência de seus/suas clientes em endereçar suas perguntas ou seus desafios terapêuticos aos comportamentos e escolhas de seus/suas interlocutoras/es. "Falar com o coração", assim, parece indicar que não há resposta certa e que Verônica pode dizer à psicóloga o que vier a sua mente com referência a pergunta colocada. ${ }^{8}$ É isso, com efeito, o que a usuária faz em sua resposta (linhas 7-10): para Verônica, sujeitos transexuais e travestis são pessoas diferentes que tem a- pensa da maneira diferente. Embora a resposta da usuária seja muito vaga com relação ao conteúdo requisitado pela pergunta, pois não especifica as diferenças que o turno de Inês necessita explicadas, a psicóloga se mostra satisfeita com a resposta (linha 11). Com seu turno da linha 11, Inês faz sua posição discursiva de professora/avaliadora mais sólida, pois aí, sequencialmente, se consolida uma sequência interacional bastante semelhante com uma dinâmica bem conhecida entre estudiosos/as de práticas em salas de aula: a sequência Iniciação-Resposta-Avaliação (IRA) (SINCLAIR E COULTHARD, 1975; MEHAN, 1979; GARCEZ, 2006). Na sequência IRA, o/a professor/a, aquele/a que detém o conhecimento, faz uma pergunta para a qual já sabe a resposta, o/a aluno/a responde e o/a professor/a avalia a ação do/a estudante em termos de certo ou errado.

Vejamos como isso se dá nessa interação. Significativamente, no entanto, a sequência IRA é, na interação psicóloga-usuária/o, manipulada de forma que ela construa para a profissional de saúde uma posição discursiva que sinalize sua função terapêutica, obscurecendo, assim, à primeira vista, seu caráter pedagógicodisciplinador. $\mathrm{O}$ corpus gerado no PAIST dá subsídios para afirmar que nas consultas de saúde mental a IRA é frequentemente interposta por uma sequência embutida durante a qual a/o usuário/a inicia um reparo à pergunta do/a profissional da saúde, indicando sua dificuldade em respondê-la. Nesse contexto, a/a profissional de saúde mental lança um turno "terapêutico" que disfarça o caráter de teste materializado por sua pergunta: Iniciação-(Reparo-Terapia)-Resposta-Avaliação, I(RT) RA:

8 No PAIST, esses turnos "terapêuticos" assumem diversas formas. As mais frequentes são: "falar com o coração", "não tem resposta certa/errada", "diga o que você pensa/acha" etc. 


\section{Excerto 2}

\begin{tabular}{|c|c|c|}
\hline 1 & Inês: & Verônica > vô pedi pra você $<$ me falá- me \\
\hline $2 \mathrm{I}$ & & explicá qual é a diferença entre transexual \\
\hline 3 & & $<$ e travesti $>\downarrow$ \\
\hline 4 & & $(4.2)$ \\
\hline $5 \mathrm{R}$ & Verônica: & ô̂:: como é ${ }^{\circ}$ que vô explicá isso, \\
\hline $6 \mathrm{~T}$ & Inês: & $>$ não precisa- $<\uparrow$ fala com seu coração Verônica \\
\hline 7 & Verônica: & que que eu a::cho? \\
\hline $8 \mathrm{R}$ & & (.) \\
\hline 9 & Verônica: & ah eu acho que $\uparrow$ são::- são pessoas diferentes \\
\hline 10 & & que tem a- pensa da maneira diferente né $=$ \\
\hline $11 \mathrm{~A}$ & Inês: & $=>$ exatamente $<\underline{\text { sentem diferente }}=$ \\
\hline
\end{tabular}

Como vemos, embora neste contexto a sequência IRA seja incrementada pela inserção de uma troca de turnos que poderíamos chamar de psicoterapêutica (linhas 5 e 6), sua trajetória se completa com a resposta de Verônica (linhas 7-10) e a avaliação de Inês (linha 11). De acordo com Garcez (2006), a IRA é rara em conversas cotidianas, mas é reconhecida em salas de aula de todo mundo e caracteriza uma interação como tendo um caráter pedagógico. Embora o autor sublinhe que "a observação dessa sequência em andamento [...] nos traria o reconhecimento de que se trata de fala-em-interação de sala de aula convencional" (ibid., p. 68), o que vemos aqui é uma conversa psicoterapêutica, em uma instituição - o hospital - que à primeira vista não teria relação com escolas a não ser pelo fato de servir como hospital de treinamento para futuros/as médicos/as. $\mathrm{O}$ embutimento do turno $T$, contudo, disfarça o tom pedagógico da sequência embora não o apague por completo, pois o que ele faz é motivar a interlocutora a elaborar uma resposta sem a preocupação com sua adequação à agenda da psicóloga.

Ostermann e Ruy (2012) observaram a ocorrência da sequência IRA em consultas obstétricas e ginecológicas. De acordo com essas autoras, o aparecimento da IRA nesse contexto é um lócus de exercício de poder médico sobre os conhecimentos "leigos" dos/as usuários/as de serviços de saúde, pois é sempre o/a médico/a que inicia a sequência e fornece correções não mitigadas no terceiro turno. Consoante Ostermann e Ruy, "a sequência IRA acontece praticamente como um preâmbulo [...] para o que vem a seguir, uma explicação médica" (2012:77). Nesse sentido, a partir dessa sequência os entendimentos cotidianos de usuários/as do SUS sobre 
seus processos de saúde/adoecimento (explicitados no segundo turno da sequência) são reentextualizados, na avaliação/correção, por saberes técnicos e, dessa forma, apagados do horizonte de ação no cuidado em saúde. O/a médico/a, nesse sentido, fala por seus/suas pacientes. Esse processo de apagamento da voz dos/as usuários/ as também é movimentado pela I(RT)RA, que caracteriza as consultas psicológicas do PAIST. O embutimento do turno $\mathrm{T}$ tem pelo menos três consequências para o desenvolvimento da consulta: (1) força o/a usuário/a a abandonar a tentativa de reparo, que não satisfaz a função da pergunta na primeira posição da sequência, (2) disfarça a agenda da pergunta, pois (3) outorga-lhe um caráter de psicoterapia apagando a possibilidade de julgamentos de valor sobre a resposta dada. Com isso, o turno T mascara o efeito pedagógico-disciplinador da sequência.

No que se refere às consultas de saúde mental do Processo Transexualizador, a ocorrência desse tipo de sequência em interações com usuários/as cujas performances corporais e narrativas divergem do modelo metapragmático de "transexual verdadeiro", indica que a função dessa especialidade vai muito além do acompanhamento psicoterapêutico do estado emocional de pessoas transexuais. ${ }^{9}$ Essa sequência permite ver os embates interacionais entre os modelos de identidade que regimentam as funções institucionais da equipe e aqueles mais locais, particulares e contingentes trazidos ao Processo por pessoas transexuais. Esses modelos de identidade não ratificados pelo saber biomédico são paulatinamente eclipsados, nos microdetalhes interacionais das consultas, pela incorporação gradual de recursos semióticos associados à narrativa universalizante solidificada como texto no DSM, processo no qual a sequência I(RT)RA tem papel central. Ademais, com essa sequência o caráter terapêutico propalado pela Portaria do Ministério da Saúde é enquadrado (GOFFMAN, 1974) por uma estrutura discursiva pedagógica com a qual usuários/as são expostos/as ao modelo metapragmático biomédico que devem sustentar em suas performances corporais e narrativas para que angariem para si o laudo que legitima suas autoidentificações e autoriza o custeio de seus cuidados sanitários. Nesse sentido, a consulta entre Verônica e Inês deixa entrever o fato de que as consultas psicológicas, ao invés de assumir para si o cuidado com a saúde emocional dos/as usuários/as como prioridade ${ }^{10}$, parecem servir de ensaio para as

\footnotetext{
9 No corpus, a I(RT)RA parece ser inexistente em consultas entre Inês e usuárias/os mais antigas/os do PAIST e que corporificam o modelo metapragmático de "transexual verdadeiro".

10 Isso não significa que profissionais de saúde mental do PAIST não se preocupassem com a qualidade dos sentimentos e dos processos de exclusão social dos/as usuários/as do PAIST. Muito pelo contrário: diferentes âmbitos da vida social, psíquica e emocional dos/as usuários/as eram terapeuticamente confrontados. Vale relembrar que tanto o DSM quanto a Resolução do CFM impõem como critério para a realização das cirurgias a inexistência de problemas psiquiátricos como depressão.
} 
consultas com o psiquiatra, responsável pela assinatura do diagnóstico, nas quais não se encontram sequências com esse formato.

Embora no fechamento da I(RT)RA Inês se mostre satisfeita com a resposta pouco precisa de sua interlocutora, a psicóloga complementa sua avaliação, indicando que travestis e pessoas transexuais sentem diferente (linha 11). Apesar de avaliar a resposta de Verônica positivamente, Inês, na quinta posição da I(RT)RA, implementa sua avaliação com uma substituição lexical: ao repetir a resposta da usuária, ao invés de usar o verbo "pensar", a psicóloga usa o verbo "sentir", enquadrando sua avaliação como uma correção. Verônica se orienta ao caráter corretivo do turno da psicóloga e, na linha 12, repete a oferta vocabular feita por Inês, modificando, assim, o que dissera anteriormente "com o coração".

A psicóloga ainda complementa essa correção e afirma que pessoas transexuais e travestis não somente sentem de formas diferentes, mas, sobretudo, tem a sexualidade diferente (linha 13, note a ênfase dada à palavra sexualidade que foi produzida de forma perceptivelmente mais lenta do que o resto do turno). $\mathrm{O}$ turno elaborado por Verônica na linha 14 pode, neste contexto, ter duas funções: (1) pode servir como complemento, em sobreposição, do turno da psicóloga iniciado na linha 13 ou (2) pode ser o complemento do turno da própria Verônica iniciado na linha 12, mas interrompido pela fala sobreposta de Inês. A psicóloga interpreta o turno de sua interlocutora como uma co-construção de seu próprio turno e, assim, na linha 16 (i:: :sso mesmo $\downarrow$ ), novamente assume sua posição discursiva de avaliadora ao julgar a contribuição da usuária como estando em consonância com o que a psicóloga vinha lhe explicando.

Os turnos negociados por Inês e Verônica entre as linhas 16 e 24 utilizam como exemplo amigas da usuária que ela identifica como travestis (provavelmente Verônica havia falado sobre essas amigas no inicio da consulta, que não foi gravada) para fazer um contraste entre como pessoas transexuais e travestis têm a "sexualidade diferente". Nas linhas 28-29, 33-34 e 37, Inês responde a pergunta que ela mesma fizera no turno da linha 1 onde se posicionava como sabendo menos do que sua interlocutora e se mostra, dessa forma, ciente das diferenças que pedira para serem explicitadas. Nesse contexto, esse turno não só responde a pergunta da linha 1, mas, sobretudo, dá a Verônica os recursos semióticos para a construção de uma narrativa de "transexual verdadeiro" que satisfaça os propósitos do Processo. O foco desses turnos é a relação que pessoas transexuais e travestis têm com seu órgão genital. Reentextualizando elementos dos saberes biomédicos que sustentam o dispositivo da transexualidade, a psicóloga explica que $<0$ transexual $>$ elena grande maioria ele não tem relação (sexual) ${ }^{\circ}$ com pênis ${ }^{\circ}$ (linhas 
28 e 29) já o travesti não $\downarrow$ eles são- tanto eles são ativos quanto eles são [passivos] (linhas 33 e 34 ). Em outras palavras, travestis U: : sam o pênis ao passo que pessoas transexuais não. Essa explicação é interposta por turnos que incitam Verônica a demonstrar que está entendendo o que a psicóloga está a lhe dizer (linhas 31 e 40). É interessante notar que a usuária, na linha 35, ajuda Inês a completar sua explicação, indicando que já sabia que travestis são tanto ativas quanto passivas em relações sexuais.

A partir da pergunta desenvolvida no turno da linha 1, da sequência I(RT)RA que ela instaura, dos turnos nos quais Inês explica qual é a diferença entre travestis e pessoas transexuais e seus constantes pedidos para que Verônica confirme que entende o que a psicóloga lhe explica, vemos Inês adotando posições discursivas pelas quais assume funções tanto de terapeuta quanto, sobretudo, de professora/ avaliadora. Verônica ratifica essas posições discursivas ao se alinhar de forma a mostrar que tem acesso epistêmico menor que Inês em questões que ela, como mulher transexual, teria experiência de primeira mão. Em sua consulta inicial no PAIST, Verônica é, destarte, exposta a certos recursos semióticos que sustentam o modelo metapragmático de "transexual verdadeiro" tanto pelo design das perguntas de Inês quanto pelas sequências interacionais organizadas ao redor dessas perguntas.

Mais adiante nesta consulta, Inês traz novamente à tona a questão da relação de pessoas transexuais com seus órgãos genitais; porém, desta feita, o contexto não era de explicação sobre as diferenças entre a travestilidade e a transexualidade, mas sim a atitude de Verônica para com seu pênis. Vale lembrar que um dos critérios centrais no DSM para o diagnóstico é a aversão à genitália que impinge um caráter de assexualidade à narrativa de "transexual verdadeiro". Trazer esse elemento contextualiza uma nova estrutura discursiva à interação (i.e. de conversa pedagógica à função diagnóstica da psicóloga) e uma nova posição para Inês (i.e., de "professora" à diagnosticadora).

\section{Excerto 3}

186 Inês:

[mas] $>$ normalmente $<$ você tem::-

187

188

189

190

191 $>$ quando você tem $<$ relação você prefere que seja?

(.)

$>$ lógico que não na rua $<$ né $=$ $=\uparrow$ não em motel [ou na casa do cara] 
192 Inês:

[em- em- em que luga] ::r- ou

193

194

195

196

209

210

211

212

213

214

215

216

217

218

219

220

221

222

223

224

225

226

227

228

229

230

231

ou na sua $=$

$=$ é $\downarrow$

você não vai na sua casa? =

= não por causa da minha família

((12 linhas omitidas))

que ele sumiu e não apareceu $\uparrow$ mais

bom e quando você tem- tem relação você:::

$<$ prefere $>$ que você fique

(.)

totalmen[te nu:::a, ]

[totalmente]::- totalmente assim à

vontade, $>$ por exemplo $<$ numa ca::ma né $\uparrow$ melhor [na rua-]

[sim mas] não te inco $\uparrow$ moda de vê assim o pê::nis?

o SEU pênis $\downarrow$

se não me incomo::da?

(.)

$n$ ::ão:: até que não

cê não se incomoda com ele,

não:::

(0.3)

e se:: o companheiro se interessa pelo seu pênis?

Verônica:

não:: até hoje n- não aconteceu $\downarrow$ de se::

interessá assim

No contexto que imediatamente precede o excerto acima, Verônica contava à Inês sobre um rapaz que conhecera enquanto estava conversando com suas amigas travestis na rua do bairro onde mora. Verônica e o rapaz se encontraram e, pelo que a usuária conta nesta e em outras consultas, tiveram uma rápida relação amorosa, 
interrompida pelo sumiço do rapaz que deixou de procurá-la e aparentemente sumiu da cidade. Na noite em que se conheceram, Verônica e este rapaz tiveram relações sexuais na rua, "num cantinho escuro". Esse episódio coloca a usuária em pelos menos dois problemas classificatórios para Inês: (1) o fato de estar acompanhada por amigas travestis e ter feito sexo na rua pode induzir sua classificação pela psicóloga como travesti profissional do sexo - um modelo de identidade que sua estilística corporal, segundo a equipe multiprofissional, sustentava - e (2) a relação sexual descrita indica que Verônica não é assexuada e pode, em suas práticas sexuais, fazer uso de seu pênis, o que circularmente a levaria a ser classifica como travesti.

No turno das linhas 210 e 211, Inês lança a pergunta que visa aferir a qualidade da relação de Verônica com seu pênis: quando você tem- tem relação você:: : <prefere> que você fique totalmen[te nu:::a, ]. O desenho da pergunta, contudo, não deixa clara a resposta diagnóstica que Inês pretende receber mas que explicita na reelaboração deste turno feita segundos mais tarde (linhas 217-218). Implicitamente, a pergunta das linhas 210-211 toma como pressuposto o fato de pessoas transexuais, como relatado na literatura psicanalítica stolleriana, preferirem usar de artifícios como calcinhas, toalhas etc. para disfarçar o órgão genital em relações sexuais que são, segundo esses relatos, raríssimas e realizadas geralmente no escuro (HEATH, 2006). Verônica, entretanto, não se orienta para esse elemento do modelo metapragmático de "transexual verdadeiro" e responde, como solicitado pela psicóloga, "com seu coração": quando tem relações sexuais ela prefere ficar totalmente nua numa cama (o que seria melhor) ou na rua, ignorando a avaliação moral da psicóloga momentos antes de que não se deve fazer sexo em lugares públicos (linha 190). Inês reelabora sua pergunta (linhas 217 e 218, [sim mas] não te incołmoda de vê assim o pê: :nis?) e deixa a função diagnóstica de sua questão clara: o incômodo com o pênis inseriria a usuária no modelo metapragmático que a pergunta pressupõe.

Após um lapso de 1.5 segundos no qual Verônica não toma o turno que a psicóloga lhe oferecera (linha 219), Inês reassume o piso conversacional e incrementa sua pergunta, deixando claro que ela falava sobre o pênis de Verônica não o de seu eventual companheiro sexual (linha 220). Apesar do que Inês havia há poucos turnos explicado sobre as diferenças entre pessoas transexuais e travestis (cf. excerto 1), a resposta de Verônica nesta consulta não reentextualiza localmente o critério diagnóstico que confirmaria seu pertencimento ao modelo de identidade que enquadra a função da pergunta de Inês neste contexto. Após pedir confirmação sobre o que a psicóloga lhe havia questionado (linha 222), Verônica afirma que seu pênis não a incomoda ( $\uparrow n:$ :ão: : até que não). Defrontando-se com a negação 
desse critério diagnóstico, Inês repete a pergunta em forma de uma formulação (HERITAGE E WATSON, 1979; OSTERMANN E SILVA, 2012) que resume seu entendimento sobre o que sua interlocutora dissera (linha 225), recebendo novamente a confirmação de que Verônica não se incomoda com seu pênis (linha 226). A psicóloga, não obstante, vai mais fundo nessa questão e inquere nas linhas 228-229 como Verônica reagiria se seu companheiro se mostrasse interessado em seu pênis, mas, segundo a usuária, até hoje n- não aconteceu $\downarrow$ de se: interessá assim.

Apesar de Inês, como vimos, ter fornecido a Verônica subsídios para que ela entendesse as diferenças entre pessoas transexuais e travestis, assim como defendido no discurso biomédico do DSM, a usuária, quando da emergência da estrutura discursiva de diagnóstico (excerto 3 ), não conseguiu reentextualizar o critério ao qual havia sido exposta no início de sua consulta, i.e., aversão ao órgão genital. A falta desse critério sobreposta à performance corporal e sexual de Verônica provocou um hiato classificatório: afinal, ela poderia ser uma travesti apesar de se dizer transexual? É a tentativa de solucionar essa dificuldade em categorizar Verônica que colorirá a segunda consulta gravada com a psicóloga, realizada em 09 de março de 2010, duas semanas após a consulta discutida até aqui. Com efeito, nesse dia, Inês não só retoma a questão da diferença entre pessoas transexuais e travestis como insere uma nova dimensão em sua tentativa de categorizar sua interlocutora. Nessa consulta, Verônica traz seus entendimentos locais sobre sua autoidentificação e se diz homossexual, pois, já que ela não é "totalmente mulher" (linhas 256-257) e se relaciona sexualmente com "homens de verdade" (ver mais adiante), ainda ter um pênis a inseriria nessa categoria identitária:

\section{Excerto 4}

$\begin{array}{lll}249 & \text { Verônica: } & \begin{array}{l}\text { eu sei:- }>\text { a mulher sofre }<\text { mas um homossexual } \\ >\uparrow \text { sofre mais que um homem }< \\ 250\end{array} \\ 251 & & (1.3) \\ 252 & \text { Inês: } & \text { você se considera um homossexual? } \\ 253 & & (2.8) \\ 254 & \text { Verônica: } & { }^{\circ} h^{\circ} \\ 255 & & (0.3) \\ 256 & \text { Verônica: } & \text { sei lá:: } \mathrm{m} \text { - m- me conside::::ro né por eu } \\ 257 & & \text { não sê totalmente mulher, } \\ 258 & & (0.5)\end{array}$




\begin{tabular}{|c|c|c|}
\hline 259 & Inês: & {$\left[{ }^{\circ}\right.$ hum::: $\left.{ }^{\circ}\right]$} \\
\hline 260 & Verônica: & [mas se E:]:U for totalmente mulher eu já \\
\hline 261 & & não vô ma::is- \\
\hline 262 & Inês: & 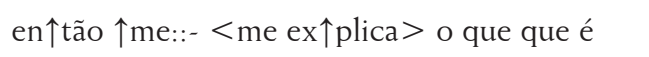 \\
\hline 263 & & $<\underline{\text { transexual }>}$ \\
\hline 264 & & $(1.1)$ \\
\hline 265 & Verônica: & ã::- transexual é::::::- é:::- >como é que é< \\
\hline 266 & & $(0.3)$ \\
\hline 267 & Verônica: & HH é por(hh)que não con[si(h)go falá (XXX)] \\
\hline 268 & Inês: & [fala com seu cora] ção \\
\hline 269 & Verônica: & $>$ transexual $<=$ \\
\hline 270 & Inês: & $=>$ o que você entende $<$ \\
\hline 71 & & $(1.3)$ \\
\hline 272 & Verônica: & 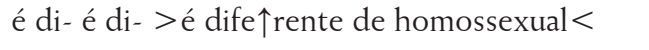 \\
\hline 273 & & homossexual [é::-] \\
\hline 274 & Inês: & [mas] você falô > que você era \\
\hline 275 & & homossexu个al< se você ta dizendo que você é \\
\hline 276 & & diferente, \\
\hline 277 & Verônica: & 个é::: o- é diferente, ã- ex me considero \\
\hline 78 & & diferente, \\
\hline 279 & & $(0.5)$ \\
\hline 280 & Inês: & mas você falô > que vo $\uparrow c \hat{e}<$ so:::: fre como um \\
\hline 281 & & homossexual, \\
\hline 282 & Verônica: & ah não mas só::- so:::fro $\downarrow>$ lógico que \\
\hline 83 & & sofro $<=$ \\
\hline 284 & Inês: & =então você é homossexual ou é transexual? \\
\hline 285 & Verônica: & 个não:::, homossexual \\
\hline 286 & Inês: & você é HOMOsexual [ > não é] trannse $[\mathrm{xual}<$ ] \\
\hline 87 & Verônica: & {$[$ não $\downarrow]$} \\
\hline 28 & & (1.7) \\
\hline
\end{tabular}

Neste momento da consulta, vemos Inês e Verônica lidando com uma dificuldade classificatória. No turno da linha 252, Inês pergunta se a usuária se considera homossexual ao que Verônica, após algumas turbulências (i.e. silêncio na linha 253, uma vocalização monossilábica na 254 e mais um lapso de tempo na 255), responde positivamente de forma truncada (i.e., alongamento de sons e 
quebras no início da resposta, indicadas com um "-_" na transcrição), o que pode indicar a delicadeza/dificuldade de lidar com o tópico sendo tratado (SILVERMAN E PERÄKYLÄ, 1990). Após um silêncio de 0.5 segundos, Verônica complementa sua resposta, em sobreposição com o continuador produzido pela psicóloga (linha 259), e explica que quando ela for "totalmente mulher" (i.e., ter uma vagina cirurgicamente construída) ela não será mais homossexual.

Nesses poucos turnos, Verônica acopla duas categorias identitárias diferentes como se fossem uma, indicando que ser homossexual equivale a ser transexual. Inês se orienta para essa confusão classificatória e, no turno da linha 262, pede que sua interlocutora explique $\circ$ que que é <transexual>, salientando a categoria que gostaria explicada em velocidade perceptivelmente mais lenta do que o restante do turno. Apesar de já ter sido exposta a uma questão semelhante na consulta que teve duas semanas antes durante a qual, como vimos, Inês lhe explicara o que caracteriza a transexualidade a la DSM, Verônica demonstra dificuldade em aventar uma resposta (linhas 265 e 267). Enquanto a usuária diz que não consegue falar (linha 267), no turno construído em sobreposição com sua interlocutora, Inês reatualiza sua posição discursiva de terapeuta, i.e., alguém que está ali para ouvi-la sem julgamentos e sem pretensões por respostas corretas, ao incitá-la, novamente, a falar com seu cora] ção (linha 268). Após confirmar a informação que a psicóloga requisitara (linha 269) e receber uma reelaboração da pergunta de forma a encorajála a falar livremente (=>0 que você entende $<$ ), Verônica, assim como na consulta anteriormente discutida, oferece outra resposta bastante vaga na qual afirma que "transexual é diferente de homossexual".

À primeira vista, com esse turno, Verônica parece nos indicar que para ela essas duas categorias identitárias são qualitativamente diferentes, contradizendo o acoplamento categorial que fizera poucos turnos antes. Inês, então, pergunta diretamente a sua interlocutora como ela se identifica: então você é homossexual ou é transexual?. Mais uma vez, Verônica se classifica como homossexual (linha 285). Para não deixar dúvidas sobre a autoidentificação de sua interlocutora, a psicóloga elabora outra pergunta polar com a qual oferece claramente duas categorias para que Verônica escolha uma. No turno da linha 285, Verônica confirma que é homossexual e não transexual.

Diante dessa autocategorização, que negaria o diagnóstico e impediria Verônica de desfrutar os serviços do PAIST ${ }^{11}$, Inês mais uma vez pede que a usuária

11 Travestis somente tiveram o atendimento em programas de transgenitalização vinculados ao Processo Transexualizador do SUS em 2013 quando da publicação da Portaria 2.803 do Ministério da Saúde que redefine e amplia o Processo (BRASIL, 2013). 
explique $\circ$ que é transexual,. Embora Verônica, na consulta do dia 24 de fevereiro, já tenha recebido uma resposta para tal questão, como vemos abaixo, ela ainda não é capaz de reentextualizar no dia 09 de março os critérios diagnósticos que Inês lhe ensinara então. A usuária não só não é capaz de demonstrar que de fato aprendeu o que é um "transexual verdadeiro" como está, nesta consulta, confundindo a categoria "transexual" com "travesti", imputando à primeira atributos que, no dia 24 de fevereiro, haviam sido designadas como características da última.

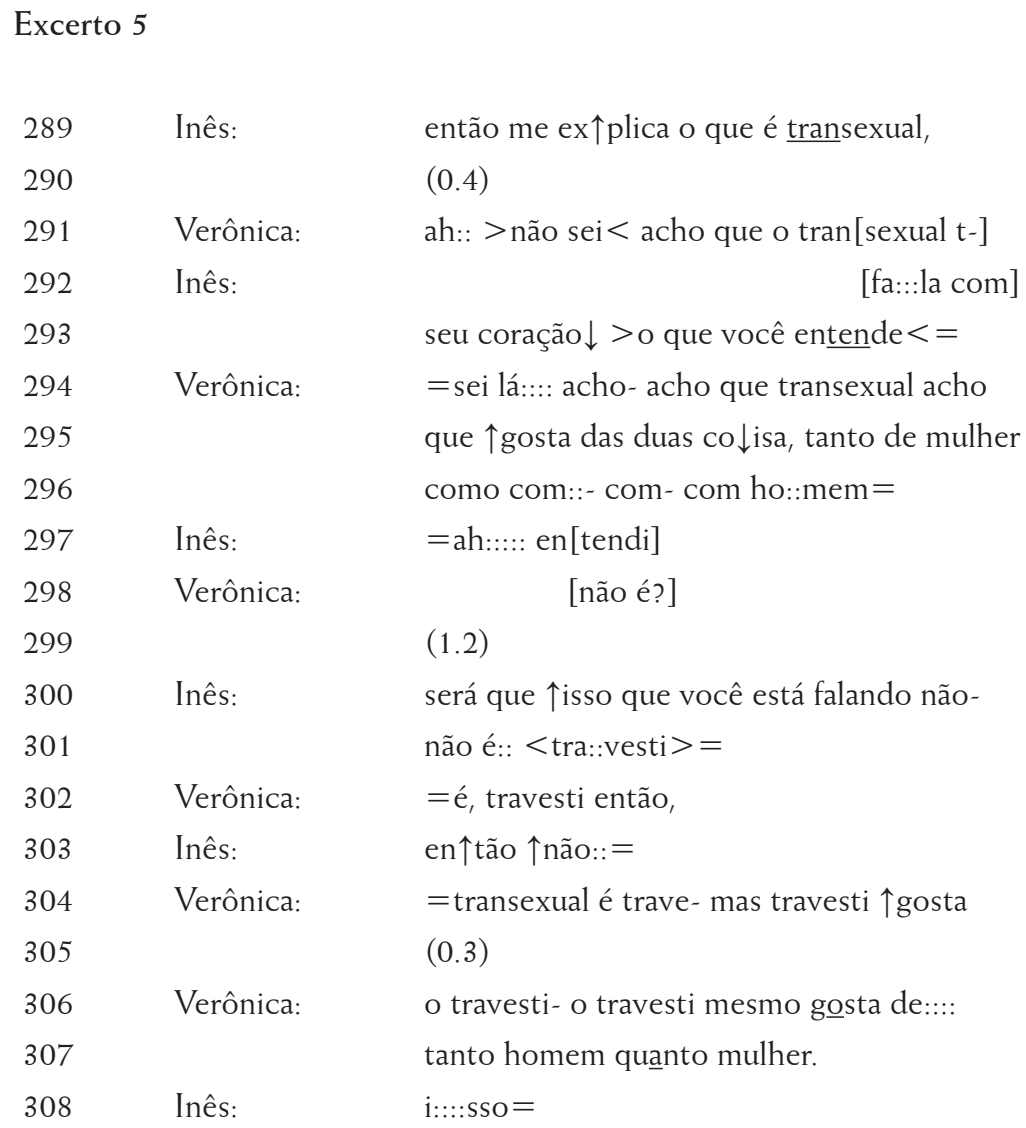

No turno desenvolvido entre as linhas 294 e 296, Verônica deixa claro que nesta consulta está tomando a categoria "transexual" por "travesti", entendendo,

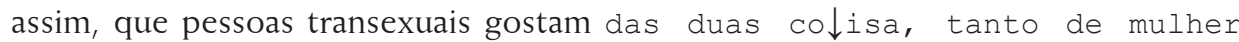
como com: :- com- com ho: :mem=, uma definição construída na consulta do 
mês anterior. Aqui vemos uma sequência de turnos que se assemelha à sequência I(RT)RA discutida anteriormente. À iniciação (linha 289), Verônica oferece, "com o coração" (linhas 292-293), uma resposta que evidencia a confusão categorial entre "transexual" e "travesti". O turno das linhas 300-301 funciona, nesse contexto, como uma avaliação na qual, com outra pergunta de resposta conhecida, a psicóloga veladamente oferta à sua interlocutora uma correção para seus entendimentos sobre essas categorias identirárias. Verônica aceita a correção na linha 302 e reelabora sua resposta, substituindo o item "transexual" por "travesti" e, dessa forma, solucionando a ambiguidade categorial que havia sido estabelecida. Contudo, a função diagnóstica da psicóloga ainda precisa endereçar a autoidentificação de Verônica como homossexual, feita momentos antes nesta consulta (cf. excerto 4).

\begin{tabular}{|c|c|c|}
\hline \multicolumn{2}{|c|}{ Excerto 6} & \multirow[b]{2}{*}{ =agora o homossexual gosta- só pa- só qué:: } \\
\hline 309 & Verônica: & \\
\hline 310 & & é só:: uma- > como é que fala < só uma::: \\
\hline 311 & & uma escolha, uma escolha diferente separada \\
\hline 312 & Inês: & pois é, então:: [>vamo vê ca-<] \\
\hline 313 & Verônica: & [gosta de üma] coisa só, \\
\hline 314 & & $>$ ho $[$ mossexual < só de homem $]$ \\
\hline 315 & Inês: & [então o ho:::mossexual] > que que é o \\
\hline 316 & & homossexual? < o homos[sexual::- \\
\hline 317 & Verônica: & [que é pas]sivo, só:: \\
\hline 318 & & $(0.4)$ \\
\hline 319 & Verônica: & é o méu caso $\downarrow$ \\
\hline 320 & & $(2.1)$ \\
\hline 321 & Inês: & $>$ olha $[$ só $<]$ \\
\hline 322 & Verônica: & [eu] entendo assim, que homossexual \\
\hline 323 & & é passivo só:::- \\
\hline 324 & Inês: & $<$ homossexual> é o::::- é o ser que gosta e \\
\hline 325 & & que tem relação com o $\uparrow$ próprio [sexo] \\
\hline 326 & Verônica: & [sexo] com \\
\hline 327 & & pes[soa do mesmo sexo] \\
\hline 328 & Inês: & [né? o meni:::nos] gostam de meninos e as \\
\hline
\end{tabular}



sente mu个lher, ele se sente homem,

Após deixar claro o que entende por travesti, Verônica explica a categoria "homossexual", com a qual havia se identificado anteriormente. Para a usuária, um homossexual [gosta de uma] coisa só, i.e., homens, e é, sexualmente falando, pas] sivo, só: :, o que é o seu caso. Mais adiante na consulta (em excerto não mostrado aqui), Verônica afirma que há homossexuais que gostam de ficar com outros homossexuais, mas que esse não é o caso dela que prefere ficar somente com homens heterossexuais. Há aqui outra confusão categorial para a qual a psicóloga se orienta e no turno da linha 324 explica que o homossexual é o ser que gosta e que tem relação com o ipróprio [sexo].

Verônica, nas linhas 326-327, mostra que sabe o que isso significa. Entretanto, a psicóloga elabora sua explicação afirmando que meni:::nos] gostam de meninos e as meninas gostam de meninas $\downarrow$. Embora a curvatura prosódica do final do turno indique que ali pode ser um lugar relevante para transição de falantes (entonação marcadamente descendente), Verônica não toma o turno (linha 330) e Inês, assim, elabora sua explicação ao implicitamente comparar "homossexual" com "transexual": mas o <homossexual:: :> Verônica ele não se sente mu个lher, ele se sente homem, e go:sta do ó- do órgão genital $\uparrow$ dele. Como sabemos, Verônica já havia sido exposta a esses signos de identidade na consulta que teve duas semanas antes. Aqui, eles intertextualmente inserem essa consulta em uma corrente discursiva (AGHA, 2007) durante a qual esta usuária, como veremos mais adiante, vai paulatinamente desaprendendo suas formas particulares de entender sua identificação de gênero e vai gradualmente adotando em suas performances narrativas os signos que performativamente a produziriam como um "transexual verdadeiro".

$\mathrm{Na}$ consulta do dia 09 de março, Inês e Verônica definiram fronteiras entre os modelos de identidade referentes a pessoas transexuais, travestis e homossexuais. $\grave{A}$ primeira vista, de acordo com as ações da usuária nessa consulta, as diferenças entre essas categorias identitárias haviam sido entendidas e aceitas como válidas. Inês, de 
fato, recicla esse tópico na abertura da terceira consulta gravada, realizada em 05 de maio de 2010: >eu me lembro< que quando nós começamos a conversá você tinha uma- uma:: uma certa:: : >cê $\uparrow$ tinha se= =colocava como $>$ travesti<. estabelecendo, assim, o pano de fundo sobre o qual a consulta se desenvolverá. Contudo, em seu turno, Verônica refuta essa classificação e a interação passará a se desenvolver ao redor da categoria "guei", utilizada pela usuária para se autocategorizar: não: :::, não é nem travesti, eu não me sinto como travesti >eu me sinto< assim geralmente eu me sinto GUEI. A partir daí, reatualiza-se a confusão categorial que Inês tentara sanar na consulta do dia 09 de março: quase assim uma mulher >totalmente< mas não- NÃO: : : total- >não posso dizê< totalmente por eu tê o órgão: : femini$<$ masculino> né comigo.

Com efeito, nessa consulta começamos a ver Verônica adotar alguns dos recursos semióticos aos quais vinha sendo exposta em suas consultas psicológicas e, com isso, seus entendimentos particulares sobre diferentes categorias identitárias começam a se dissipar:

\begin{tabular}{|c|c|c|}
\hline \multicolumn{3}{|c|}{ Excerto 7} \\
\hline 539 & Inês: & $=$ essa é Uma ou é a única maneira de \\
\hline 540 & & dife[renciá-] \\
\hline 541 & Verônica: & {$[$ não $\downarrow$ é u] :::ma } \\
\hline 542 & & $(0.4)$ \\
\hline 543 & Inês: & e qual a se- qual você acha que seria a \\
\hline 544 & & $<$ outra $>$ ? \\
\hline 545 & & $(8.1)$ \\
\hline 546 & Verônica: & .hhh bom $\downarrow$ geralme- o travesti::::: \\
\hline 547 & & $(0.3)$ \\
\hline 548 & Verônica: & $>$ geralmente travestíi< é o que eu fiquei já \\
\hline 549 & & sabẹndo né, não::::: tem vontade de fazê \\
\hline 550 & & essa cirurgia, \\
\hline 551 & & $(0.7)$ \\
\hline 552 & Verônica: & agora eu acredito- $>>$ sei lá $<<$ a trans- a \\
\hline 553 & & <transexual > já::::: \\
\hline 554 & & $(0.4)$ \\
\hline
\end{tabular}




\begin{tabular}{|c|c|c|}
\hline 555 & Verônica: & já tem vontade de fazê a ci[rur $\uparrow$ gia] \\
\hline 556 & Inês: & [en $\uparrow$ tão] começando \\
\hline 557 & & por essa maneira de pensá, é::::: porque será \\
\hline 558 & & que o transexual qué fazê: $>$ a cirurgia $<\uparrow$ e o \\
\hline 559 & & travesti não $\downarrow$ qué? \\
\hline 560 & & (.) \\
\hline 561 & Inês: & pois se $<<$ aparentemente $>>>$ eles são iguais $<$ \\
\hline 562 & & $(4.2)$ \\
\hline 563 & Verônica: & sei lá::: XXXX= \\
\hline 564 & Inês: & $=$ pensa Verônica, [pensa $\downarrow]$ \\
\hline 565 & Verônica: & [às ve(hhh)]zes-@@@às \\
\hline 566 & & vezes é:::::: \\
\hline 567 & & $(0.5)$ \\
\hline 568 & Verônica: & não $\uparrow$ sei:::, não- não vô dizê tọdos > mas às \\
\hline 569 & & vezes $<$ tem algüm transexual que não se sente \\
\hline 570 & & 个bem:: \\
\hline 571 & & (.) \\
\hline 572 & Verônica: & né? \\
\hline 573 & & $(0.6)$ \\
\hline 574 & Inês: & ${ }^{\circ}(\mathrm{como} ?)^{\circ \circ}$ \\
\hline 575 & Verônica: & ah sei $\uparrow l a ́$, não se sente bem, \\
\hline 576 & & $(0.7)$ \\
\hline $\begin{array}{l}577 \\
\text { jeito }\end{array}$ & Verônica: & $<<$ em sê::: $>>>>$ em- em- em- $<<$ em $\underline{\text { sê do }}$ \\
\hline 578 & & que é, \\
\hline 579 & & $(0.3)$ \\
\hline 580 & Verônica: & né? \\
\hline 581 & & $(0.4)$ \\
\hline 582 & Inês: & ${ }^{\circ \circ}$.hh ta bom ${ }^{\circ \circ}$ \\
\hline
\end{tabular}

Diante da autocategorização de Verônica como homossexual, Inês retoma a discussão sobre diferentes modelos de identidade que tomou a consulta anterior 
por completo. Após reatualizar nessa interação a definição de homossexual que havia feito anteriormente e, assim, deixando claro que "transexual" e "guei" são coisas bem diferentes, Inês pergunta novamente a sua interlocutora as diferenças entre pessoas transexuais e travestis. Note que Tanto Inês quanto Verônica usam o termo "travesti" com o masculino gramatical. Esse uso é contrário às escolhas linguísticas e políticas feitas por travestis. Como Borba e Ostermann (2007; 2008) explicam, o feminino gramatical é normalmente utilizado com referência ao substantivo "travesti" em um grupo de travestis profissionais do sexo no sul do Brasil - uma manipulação clara do sistema linguístico do Português brasileiro para o qual a palavra travesti é um substantivo masculino. $\mathrm{O}$ uso do sintagma "a travesti" também foi verificado em outras regiões do país (ver, por exemplo, PELÚCIO, 2009). Borba e Ostermann $(2007 ; 2008)$ descrevem que, apesar desta escolha, o masculino gramatical é utilizado em determinados contextos e servem funções interacionais bastante específicas, por exemplo, marcar o período da vida antes das modificações corporais e salvaguardar a imagem pública de travestis quando descrevem atitudes de outras travestis com as quais as falantes não se identificam.

A usuária explica que travestis normalmente trabalham como profissionais do sexo (excerto não mostrado) e, a partir daí, a psicóloga questiona se essa é a única diferença (linha 539). Verônica, tendo indicado que "fazer programas" é uma das formas de diferenciar essas categorias identitárias, afirma que travestis geralmente não têm vontade de fazer a cirurgia de transgenitalização ao passo que pessoas transexuais têm (linhas 548-555). Não é difícil entrever aqui ecos dos modelos de identidade que Inês havia construído nas consultas anteriores e que Verônica não reentextualizou no início desta consulta. Em outras palavras, no dia 05 de maio, vemos o início de pequenos abalos nos entendimentos particulares da usuária sobre essas categorias e, com isso, ela adota as definições que Inês vinha defendendo desde a primeira consulta. É interessante notar que em seu turno a usuária faz uso de muitos recursos atenuantes do grau de certeza de sua resposta e que a distanciam da informação sendo oferecida: prefácios (.hhh bom $\downarrow$ geralme-, é o que eu fiquei já), truncamento de palavras (geralme-) e alongamentos de som (o travesti: : : : : ). Embora Verônica não cite a fonte de seu conhecimento, simplesmente indicando que "ficou sabendo", sabemos que esse elemento de diferenciação foi repetidamente evocado por Inês nas consultas anteriores.

Finalmente, em maio a usuária inicia o processo de reentextualização em consultório dos signos de identidade aos quais havia sido exposta desde sua entrada no PAIST em fevereiro. Inês, no entanto, vai mais a fundo nesta questão e pergunta as razões pelas quais pessoas transexuais querem fazer a cirurgia já que elas 
e travestis <<aparentemente>> >eles são iguais $<$. Essa pergunta pressupõe a diferenciação feita já na consulta do dia 24 de fevereiro e repetida no dia 09 de março: travestis usam o pênis e não o rejeitam ao passo que pessoas transexuais não se identificam com essa parte de seu corpo e desejam extirpá-la. Repetindo o padrão de distanciamento epistêmico ao que fala, a usuária afirma que não- não vô dizê tôdos >mas às vezes é: : : : : : 个bem: : Inês, contudo, não assume o turno que Verônica lhe oferecera e é convidada a avaliar sua resposta com né? (linha 572).

Ao invés de adotar a posição discursiva que Verônica lhe incitara, a psicóloga pede que ela elabore sua resposta. Embora a usuária tenha, com sucesso, reentextualizado ali e então signos de identidade que antes não fazia uso, Inês se mostra insatisfeita com essa resposta, pois ainda faltam aí elementos centrais sobre os quais a usuária já havia sido ensinada, notadamente a aversão ao órgão genital. Verônica, entretanto, não repete esse signo e simplesmente conclui que pessoas transexuais não se sentem bem do jeito que são. Claramente, a usuária não havia até então aprendido a lição. Apesar disso, no turno da linha 582 a psicóloga indica que aceita (temporariamente) a resposta e passa, a partir daí, a focalizar a diferença entre pessoas transexuais e homossexuais.

Porém, apesar de na consulta do dia 05 de maio Inês ter se mostrado satisfeita com a diferenciação que Verônica havia feito e que repetia alguns signos de identidade que a psicóloga lhe havia ensinado, na quarta consulta gravada, realizada no dia 09 de junho, o assunto volta a ser a autoidentificação da usuária. Nesta consulta, no entanto, Verônica não só reentextualiza os critérios diagnósticos do DSM para descrever "transexuais verdadeiros", mas, sobretudo, os aplica a si mesma, contradizendo a performance narrativa elaborada para/com Inês em sua primeira consulta no programa e, assim, evidencia o eficiente processo de assujeitamento ao modelo metapragmático de "transexual verdadeiro" movimentado pelo Processo:

\section{Excerto 8}

$\begin{array}{lll}123 & \text { Inês: } & \text { o transexual }>\text { não é travesti }<= \\ 124 & \text { Verônica: } & =\text { não } \\ 125 & \text { Inês: } & \text { preste bem atenção } \downarrow \text { o transexual é diferente } \\ 126 & & \text { de travesti, } \\ 127 & & (0.3) \\ 128 & \text { Inês: } & <\text { travesti }>\text { ele s:::- ele- ele- é:::: ele tem } \\ 129 & & \text { um corpo de ho::::mem, ele gosta de homem no } \\ 130 & & \text { caso MAS gosta de vesti de mulher, porque }\end{array}$


131

136

140

141

142

143

144

145

146

147

148

149

150

151

152

153

154

155

156

157

158

159

160

161

162

163

164

165 vestir se de mulher é:::: faz com que eles

se sintam diferentes [dá um:::-]

Verônica:

[mas tem] muitos

transexuais também [que-]

[tran] sexual não $\downarrow$ travesti

não:: $>$ então $<$ mas tem muitos travestis

também $>$ igual a senhora falô $<$ que se veste

de mulher, gosta de ho- gosta de se vesti de

mulher e que gostam < $\underline{\text { tanto }}$ de homem $>$ quanto

de mulher,

(.)

que tem lá no meu- lá na minha cidade,

(0.4)

já o <transexual> é::: u- uma pessoa que

a:::cha- que sente $>$ acha não $<$ SENTE que nasceu no corpo er $\uparrow$ rado, < se sente mulher $>$ e- $>$ não é só porque se veste de mulher $<$ mas se $\uparrow$ sente mulher e não gosta do corpo que tem $\downarrow$

(.)

no caso com o pênis, diferente do travesti,

o travesti nem pensa de fazê uma cirurgia de tirá o pênis,

mas então o caso é o mẹu caso $\downarrow$

qual é o seu caso? =

= esse que a senhora falô, que::- é::- assim

eu gosto de meu corpo eu só não $\uparrow$ gosto do::-

é::- > no caso $<$ do órgão genital que eu tenho

(.)

por quê? porque isso me incomo::da e além de me incomodá::: [mui] tas vezes me prejudica [hum?]

(0.3)

de eu ficá com o ca::::ra > entendeu? $<$

entendi 
No início deste excerto, Inês retoma a questão da diferença entre pessoas transexuais e travestis, repetindo o que já havia sido estabelecido nas consultas anteriores e parcialmente replicado por Verônica no dia 05 de maio. Com essa explicação, Inês oferta a sua interlocutora certos signos de identidade que indexicalizam os modelos que vêm povoando as consultas. Essa repetição serve de pano de fundo para a autoidentificação de Verônica realizada no turno das linhas 156 e 159: eu gosto de meu corpo eu só não †gosto do: :- é: :- >no caso< do órgão genital que eu tenho. Relembremos, no entanto, o que acontecera na primeira consulta que Verônica teve no PAIST, em fevereiro:

$\begin{array}{lll}\text { Excerto } 9 & & \\ 217 & \text { Inês: } & \\ 218 & & \text { psim mas] não te inco } \uparrow \text { moda de vê assim o } \\ 219 & & (1.5) \\ 220 & \text { Inês: } & \text { o SEU pênis } \downarrow \\ 221 & & (0.9) \\ 222 & \text { Verônica: } & \text { se não me incomo::da? } \\ 223 & & (.) \\ 224 & \text { Verônica: } & \uparrow n:: a ̃ o:: \text { até que não } \\ 225 & \text { Inês: } & \text { cê não se incomoda com ele, } \\ 226 & \text { Verônica: } & \text { não::: }\end{array}$

O contraponto entre as performances narrativas elaboradas por Verônica em sua primeira consulta no dia 24 de fevereiro de 2010 - na qual não reentextualizou o critério diagnóstico "aversão ao pênis" - e as desenvolvidas no dia 09 de junho permite observar como a usuária do PAIST foi paulatinamente reestilizando os signos de identidade utilizados para/com Inês e, assim, desaprendeu a "ser". Em outras palavras, durante sua história interacional com a psicóloga, Verônica gradualmente deixa em suspenso as autoidentificações que trouxera consigo quando de sua entrada no PAIST e aprende, nos microdetalhes de suas relações intersubjetivas com a profissional de saúde, a incorporar e performar o modelo metapragmático de "transexual verdadeiro". Esse (des)aprendizado se deu de forma insidiosa e pulverizada: nas relações intertextuais entre eventos comunicativos, durante vários meses, através dos quais certos signos de identidade circularam, a usuária foi exposta aos recursos semióticos que deveria utilizar para desenvolver uma performance narrativa que satisfizesse a Resolução do CFM e pudesse ter suas necessidades sanitárias atendidas no SUS. Como observa Borba (2014b; 
2016), as interações entre usuárias/os transexuais que acontecem fora do hospital também têm papel importante nesse processo de (des)identificação. De fato, pessoas transexuais compartilham sugestões de como estilizar uma performance corporal e narrativa que estrategicamente satisfaça as necessidades diagnósticas do Processo Transexualizador. Ou seja, se, como Foucault argumenta, onde há poder, há resistência, o aprendizado dessa narrativa é o resultado tanto das interações entre usuários/as e profissionais de saúde em consultório quanto do que acontece fora do consultório quando pessoas transexuais confeccionam formas de enfrentar o imperativo diagnóstico.

As análises apresentadas nesta seção traçam o itinerário de solidificação e corporificação de somente um dos critérios diagnósticos (i.e., aversão ao órgão genital). No entanto, embora Verônica tenha com sucesso reentextualizado esse critério para Inês em junho de 2010, suas performances corporais e narrativas ainda causavam fissuras no modelo de "transexual verdadeiro" e, dessa forma, sua trajetória de socialização ainda não estava terminada então. Discuti aqui somente uma fase no processo durante o qual as performances de Verônica foram introduzidas na metapragmática do dispositivo da transexualidade que projeta o que e como usuários/as de programas de transgenitalização podem dizer e mostrar às equipes desses serviços e, em contrapartida, limita como profissionais de saúde, independente de suas opiniões sobre a patologização da transexualidade, devem ver e ouvir seus/suas interlocutores/as.

As análises apresentadas aqui mostram como Verônica gradual e cumulativamente aprendeu a falar como um "transexual verdadeiro". Em sua história interacional com a psicóloga, o discurso do mundo cotidiano que Verônica trouxera consigo quando chegou ao PAIST - ou seja, suass próprias visões e descrições de suas experiências corporais e subjetivas - foi eclipsado pelo discurso da medicina (MISHLER, 1984). Esse processo de socialização em discursos patologizantes aconteceu através dos links intertextuais entre vários eventos comunicativos no decorrer de muitos meses. $\mathrm{O}$ uso repetido de certos signos de identidade liga as consultas uma a outra e contribui para que Verônica se familiarize com o discurso que ela deve usar para projetar uma performance identitária que satisfaça as imposições do Conselho Federal do Medicina para diagnosticar "transexuais verdadeiros". Nesse contexto, a exigência institucional do diagnóstico movimenta processos micro-interacionais de governo de si e do outro que acabam transformando indivíduos em tipos reconhecíveis de sujeitos (trans). 


\section{CONSIDERAÇÕES FINAIS}

O estudo de caso discutido neste artigo ilustra como a imposição de um diagnóstico no Processo Transexualizador brasileiro movimento processos intersubjetivos de deslegitimação (BUCHOLTZ E HALL, 2005) das vozes e experiências que pessoas transexuais trazem consigo para os programas de transgenitalização. A necessidade do diagnóstico impõe às interações entre profissionais de saúde e usuários/as trans estruturas interacionais e posições discursivas nas quais tais profissionais atuam como juízes das performances identitárias dos/as usuários/as. Nas consultas, profissionais de saúde oferecem a seus/suas interlocutores/as um vocabulário para que possam satisfazer as demandas narrativas (COUPLAND ET. AL., 2005) exigidas pelo CFM.

$\mathrm{O}$ processo de desaprender formas não-ratificadas de transexualidade é o resultado intertextual do design das perguntas e sua sequencialidade na interação e, centralmente, das ofertas lexicais elaboradas por profissionais de saúde na sequência I(RT)RA. A produção interacional de "transexuais verdadeiros", assim, emerge cumulativamente da série de interações pelas quais usuários/as são socializados nesse modelo metapragmático de identidade. Ou seja, nos microdetalhes dessas consultas pessoas transexuais aprendem a vigiar e disciplinar suas ações sociais para que possam ter acesso às tecnologias médicas do SUS. As dinâmicas de assujeitamento discutidas por Foucault em seu trabalho, assim, tomam corpo nos detalhes mais ínfimos e quase imperceptíveis da vida diária de usuários/ as no Processo Transexualizador (nesse sentido, ver RAMPTON, 2014). Pouco a pouco os sistemas de conhecimento que produziram o modelo de "transexual verdadeiro" são corporificados nas performances identitárias dos/as usuários/as trans, constrangendo, assim, suas possibilidades de (identific)ação.

A exigência do diagnóstico, portanto, enquadra a assistência à saúde transespecífica em práticas institucionais de pan-optismo disciplinar. Em outros termos, o Processo Transexualizador disciplina (e pune) performances que contradizem o modelo de "transexual verdadeiro". Nesse contexto, profissionais de saúde sabem tudo, veem tudo e escutam tudo. Nos micro-detalhes de suas interações com pessoas transexuais, eles/as acabam por impor formas "legítimas" de ser uma pessoa transexual aos/às usuários/as que devem aprender o que e como falar para serem classificados/as como "transexuais verdadeiros" e ter seu cuidado em saúde garantido. Nesse sentido, a exigência do diagnóstico engendra processos interacionais que conectam o governo dos outros e o governo de si. Profissionais de saúde moldam as compreensões de usuários/as sobre seus corpos e identidades; pessoas transexuais, 
por sua vez, são forçadas a monitorar suas performances identitárias e linguísticas para que garantam o diagnóstico e tenham acesso às cirurgias de redesignação sexual e à terapia hormonal.

No nível analítico, a justaposição da genealogia foucaultiana de discursos, sistemas de conhecimento e as práticas de categorização que engendram com uma análise interacional de inspiração goffmaniana apresentada neste artigo contribui para que entendamos como fenômenos macro-sociológicos (i.e., a patologização da transexualidade e gênero) retroalimentam e constrangem os micro-detalhes de relações intersubjetivas locais. Consoante Hacking (2004), tanto Foucault quanto Goffman são importantes para que entendamos como classificações de pessoas interagem com as pessoas por elas atingidas.

Como tentei argumentar acima, o estudo da trajetória de socialização no modelo metapragmático de "transexual verdadeiro" acontece na interseção entre uma abordagem histórico-política foucaultiana e um estudo goffmaninano etnograficamente sensível aos detalhes quase imperceptíveis de nossas ações sociais. Nesse sentido, o estudo das dinâmicas de desaprendizagem de si, de dinâmicas identitárias e intersubjetivas contribui para que reaprendamos a olhar nossos dados e, sobretudo, extrapolar suas fronteiras textuais, focalizando sua produção semiótica no tempo, na história e nos âmbitos macro-sociológico e macropolítico que sedimentam certas interpretações para signos de identidade. Ou seja, tal investigação necessita de um olhar microscópico e etnográfico para os detalhes das ações sociais enquadrado por uma visão telescópica da história que delineia sua indicialidade: precisamos da pragmática e da metapragmática, de Goffman e Foucault.

\section{REFERÊNCIAS BIBLIOGRÁFICAS}

AGHA, A. (2007). Language and Social Relations. Cambridge:CUP.

ARÁN, M. (2006). A Transexualidade e a gramática normativa dos sistemas de sexogênero. Ágora, IX/1, p. 49-63.

ARÁN, M.; MURTA, D.; LIONÇO, T. (2009). Transexualidade e Saúde Pública no Brasil. Ciência \& Saúde Coletiva, 14, p. 1141-1149.

AVELINO, N. (2010). Foucault e a arqueologia dos saberes. In.: FOUCAULT, Michel, O governo dos vivos. São Paulo:Centro de Cultura Social, Rio de Janeiro:Achiamé, p.7-27.

BAUMAN, R.(2004). A World of Others`s Words: Cross-cultural perspectives on intertextuality. Oxford: Blackwell.

BENJAMIN, H. (1966/1999). The Transsexual Phenomenon. Dusseldorf:Symposium Publishing. 
BENTO, B. (2006). A Invenção do Corpo: Sexualidade e Gênero na Experiência Transexual. Rio de Janeiro:Garamond.

BENTO, B. (2008). O que é Transexualidade? São Paulo:Brasiliense.

BILLIG, M. (1999). Conversation Analysis and the claims of naivity. Discourse and Society $10 / 4$, p. $572-576$.

BORBA, R. (2016). O (des)aprendizado de si: transexualidades e interação na clínica médica. Rio de Janeiro:FioCruz.

BORBA, R. (2014a). (Des)aprendendo a "ser": trajetórias de socialização e performances narrativas no Processo Transexualizador. Tese (Doutorado). Universidade Federal do Rio de Janeiro. Programa Interdisciplinar de Pós-Graduação em Linguística Aplicada.

BORBA, R. (2014b). Sobre os obstáculos discursivos para a atenção integral e humanizada à saúde de pessoas transexuais. Sexualidad Salud y Sociedad, vol. 17, p. 66-97.

BORBA, R.; OSTERMANN, A. C. (2007). Do bodies matter? Travestis' embodiment of (trans)gender identity through the manipulation of the Brazilian Portuguese grammatical gender system. Gender and Language 1/1, p. 131-147.

BORBA, R.; OSTERMANN, A. C. (2008). Gênero Ilimitado: a construção discursiva da identidade travesti através da manipulação do sistema de gênero gramatical. Revista Estudos Feministas, 16, p. 409-432.

BRASIL. (2010). Conselho Federal de Medicina. Resolução 1.955 de 18 de agosto de 2010. Dispõe sobre a cirurgia de transgenitalismo. Diário Oficial da União, n. 170, seção 1, p. 109-110.

BRASIL. (2013). Ministério da Saúde. Portaria 2.803 de 19 de novembro de 2013. Redefine e amplia o Processo Transexualizador no Sistema Único de Saúde. Diário Oficial da União, n. 226, seção 1, p. 25-30.

BUCHOLTZ, M.; HALL, K. (2005). Identity and interaction. Discourse Studies, 7/4-5, p. 585-614.

BUTLER, J. (1990/2003). Problemas de Gênero: Feminismo e a Subversão da Identidade. Rio de Janeiro:Civilização Brasileira.

BUTLER, J. (2004). Undoing gender. Nova York:Routledge.

CAMARGO JR., K. (1997). A biomedicina. Physis: Rev. De Saúde Coletiva, 7/1, p.45-68.

CASTEL, P. (2001). Algumas reflexõess para estabelecer a cronologia do "fenômeno transsexual (1910-1995). Revista Brasileira de História, 21/41, p. 77-111.

COUPLAND, N.; GARRET, P.; WILliAMS, A. (2005). Narrative Demands, Cultural Performance and Evaluation:Teenage boys' Stories for their Age-peers. In.: THORNBORROW, Joanna e Jennifer COATES (eds.), The Sociolinguistics of Narrative. Amsterdam:John Benjamin Publishing Co, p.67-88.

DELEUZE, G. (1990). ¿Que és un dispositivo? In.: Michel Foucault, filósofo. Barcelona:Gedisa, p. 155-161.

FABRÍCIO, B. F. (2007). Co-participação tático-reflexiva: formas de (inter)ação na sala de aula de LE com potencial democrático. Calidoscópio, 5, p. 125-138. 
FOUCAULT, M. (1963/2001). O Nascimento da clínica. $7^{\text {a }}$ edição. Rio de Janeiro:Forense Universitária.

FOUCAULT, M. (1975/2011). Vigiar e Punir. 39a edição. São Paulo:Vozes, 1975/2011.

FOUCAULT, M. (1976/2003). História da sexualidade: a vontade de saber vol. I. Rio de Janeiro:Graal, 1976/2003.

FOUCAULT, M. (1979/2013). Microfísica do poder. 27ª edição. São Paulo:Graal.

FOUCAULT, M. (1982/2010). O sujeito e o poder. In.: DREYFUS, H. e P. RABINOW. Michel Foucault: uma trajetória filosófica. Rio de Janeiro:Forense Universitária, p. 273-295.

FOUCAULT, M. (1988). Technologies of the self. In.: P. H. HUTTON, H. Gutman \& L. H. MARTIN (eds.), Technologies of the self: a seminar with Michel Foucault. Anherst: The University of Massachusetts Press, p. 16-49.

FOUCAULT, M. (1993). Verdade e subjetividade. Revista de Comunicação e Linguagem 1/19: 203-223.

FOUCAULT, M. (2009). O governo dos vivos - Curso no Collège de France, 1979-1980. São Paulo:Centro de Cultural Social.

FOUCAULT, M. (2007). A arqueologia do saber. Rio de Janeiro:Forense Universitária.

GARCEZ, P. (2006). A organização da fala-em-interação na sala de aula: controle social, reprodução de conhecimento, construção conjunta de conhecimento. Calidoscópio 4/1: 66-80.

GOFFMAN, E. (1959). The Presentation of Self in Everyday Life. Nova York:Anchor Books.

GOFFMAN, E. (1964/2002). A situação negligenciada. In.: RIBEIRO, Branca e Pedro GARCEZ (orgs.), Sociolinguística Interacional. São Paulo:Edições Loyola, p. 13-20.

GOFFMAN, E. (1974). Frame Analysis:An Essay on the Organization of Experience. Boston:Northeastern University Press.

GOFFMAN, E. (1979/2002) Footing. In.: RIBEIRO, Branca e Pedro GARCEZ (orgs.), Sociolinguística Interacional. São Paulo:Edições Loyola, p. 107-148.

GOMES DE JESUS, J. (2012). Orientações sobre identidade de gênero: Conceitos e Termos. $1^{\mathrm{a}}$ ed. Goiânia:Ser-tão - Núcleo de estudos e pesquisas em gênero e sexualidade/UFG.

HACKING, I. (2004). Between Michel Foucault and Erving Goffman: Between discourse in the abstract and face-to-face interaction. Economy and Society 33/3:277-302.

HEATH, R. (2006). The Praeger Handbook of Transsexuality: Changing gender to match mindset. New York:Greenwood.

HERITAGE, J. (2010). Questioning in medicine. In.: FREED, Alice e Susan EHRLICH (eds.), Why do you ask? The function of questions in institutional discourse. Oxford:Oxford University Press, p. 42-68.

HERITAGE, J.;WATSON, R. (1979). Formulations as conversational objects. In.: PSATHAS, George (ed.), Everyday Language. Nova York:Irvington Press, p.83-99.

HIRD, M. (2002). For a sociology of transsexualism. Sociology 36/3:577-595.

JEFFERSON, G. (2004). Glossary of Transcript Symbols with an Introduction. In.: LERNER, Gene (ed.), Conversation Analysis: Studies from the First Generation. Amsterdam:John Benjamins, p. 13-31. 
KENDAL, S. (2008). The Balancing Act: Framing Gendered Parental Identities at Dinnertime. Language in Society, 37/4, p. 539-568.

KOSHIK, I. (2010). Questions that convey information in teacher-student conferences. In.: FREED, Alice e Susan EHRLICH (eds.), Why do you ask? The function of questions in institutional discourse. Oxford:Oxford University Press, p. 159-186.

LAU, C.; OSTERMANN, A. C. (2005). As interações no telemarketing ativo de cartão de crédito: da oferta velada à rejeição. ALFA 49/2, p. 65-88.

LIMA, F. (2011). A invenção do dispositivo da transexualidade: produções de verdade e experiências trans. Em Pauta 9/28:117-130.

LIMA, F. (2014). Corpos, gêneros, sexualidade: políticas de subjetivação - textos reunidos. 2.ed. rev. atual. Porto Alegre: Rede UNIDA.

LODER, L. (2008). Noções fundamentais: a organização do reparo. In.: LODER, Letícia e Neiva Maria JUNG (orgs.), Fala-em-interação social: introdução à análise da conversa etnometodológica. Campinas:Mercado de Letras, p. 95-126.

LODER, L.; SALIMEN, P.; MÜLLER, M. (2008). Noções fundamentais: sequencialidade, adjacência e preferência. In.: LODER, Letícia e Neiva Maria JUNG (orgs.), Falaem-interação social: introdução à análise da conversa etnometodológica. Campinas:Mercado de Letras, p. 39-58.

MARTÍNEZ-GUZMÁN, A.; INIÍGUEZ-RUEDA, L. (2010). La fabricación del transtorno de identidad sexual. Discurso \& Sociedad 4/1:30-51.

MEHAN, H. (1979). Learning lessons. Cambridge, MA:Harvard University Press.

MISHLER, E. (1984). The discourse of medicine: Dialectics of medical interviews. Harvard:Greenwood. MURTA, D. (2007). A Psiquiatrização da Transexualidade:Análise dos Efeitos do Diagnóstico de Transtorno de Identidade de Gênero sobre as Práticas de Saúde. Dissertação de Mestrado. Instituto de Medicina Social, Universidade do Estado do Rio de Janeiro, Rio de Janeiro.

MURTA, D. (2011). Os desafios da despatologização da transexualidade: reflexões sobre a assistência a transexuais no Brasil. Tese de Doutorado. Instituto de Medicina Social, Universidade do Estado do Rio de Janeiro, Rio de Janeiro.

NEWMAN, L. (2000). Transgender Issues. In.: USSHER, J (ed.), Women's Health: Contemporary international perspectives. Leicester:BPS Books, p. 394-404.

OSTERMANN, A. C.; RUY, R. (2012). As relações de poder nas consultas ginecológicas e obstétricas. In.: OSTERMANN, Ana Cristina e Stella MENEGHEL (orgs.). Humanização. Gênero. Poder: Contribuição dos estudos de fala-em-interação para a atenção em saúde. Rio de Janeiro e Campinas:Editora Fiocruz e Mercado de Letras, p. 65-81.

OSTERMANN, A. C.; RUY, R.; SILVA, C. (2012). A formulação explicitando a compreensão mútua entre médico e paciente: uma forma de humanizar os atendimentos. In.: OSTERMANN, Ana Cristina e Stella MENEGHEL (orgs.). Humanização. Gênero. Poder: Contribuição dos estudos de fala-em-interação para a atenção em saúde. Rio de Janeiro e Campinas:Editora Fiocruz e Mercado de Letras, p. 119-132. 
PELÚCIO, L. (2009). Abjeção e desejo: Uma etnografia travesti sobre o modelo preventivo de AIDS. São Paulo:Annablume.

POMERANTZ, A. (1984). Agreeing and disagreeing with assessments: some features of preferred/dispreferred turn shapes. In.: ATIKINSON, J. M. e John HERITAGE (eds.), Structures of Social Action. Cambridge:CUP, p. 57-101.

RABINOW, P. (2002). Antropologia da razão. Rio de Janeiro:Relume Dumará.

RAMPTON, B. (2014). Gumperz and Governmentality in the 21st century: interaction, power, and subjectivity. Working Papers in Urban Language and Literacies, n. 136.

ROSE, N. (1999). The power of freedom. Cambridge:CUP.

SCHEGLOFF, E. (1968). Sequencing in conversational openings. American Antbropologist 70, p. 1075-1095.

SCHEGLOFF, E.; JEFFERSON, G.; SACKS, H. (1977). The preference for self-correction in the organization of repair in conversation. Language 53/2, p. 361-382.

SILVERSTEIN, M.; URBAN, G. (1996). Natural bistories of discourse. Chicago:The University of Chicago Press.

SINCLAIR, J.; COULTHARD, M. (1975). Towards an analysis of discourse: The English used by teachers and pupils. London:Oxford University Press.

SPEER, S. (2009). Passing as a transsexual woman in the gender identity clinic. In.: WETHERELL, Margareth (ed.), Theorizing Identities and Social Action. Basingstoke: Palgrave Macmillan, p. 116-138.

SPEER, S. (2010). Pursuing views and testing commitments: The role of 'worst case' hypothetical questions in the psychiatric assessment of transsexual patients. In.: FREED, Alice e Susan EHRLICH (eds.), Why do you ask? The function of questions in institutional discourse. Oxford:Oxford University Press, p. 133-158.

SPEER, S. (2011). On the role of reported, third party compliments in passing as a 'real' woman. In. SPEER, Susan e Elizabeth STOKOE (eds.), Conversation and Gender. Cambridge: Cambridge University Press, p. 155-182.

STOLLER, R.. (1975/1982). A Experiência Transexual. Rio de Janeiro:IMAGO.

STONE, S. (1991/2007). The Empire Strikes back: The posttranssexual manifesto. Disponível em http://sandystone.com/empire-strikes-back

TEIXEIRA, F. (2013). Dispositivos de dor: saberes-poderes que (con)formam as transexualidades. São Paulo:Annablume.

VEHVILAINEN, S. (2011). Identifying and managing resistance in psychoanalytic interaction. In. PERÄKYLÄ, Anssi; Charles ANTAKI; Sana VEHVILAINEN e Ivan LEUDAR (eds.), Conversation Analysis and Psychotherapy. Cambridge:CUP, p. 120-138. WITTGENSTEIN, L. (1953/2000). Investigações filosóficas. São Paulo: Nova Cultural.

WORTHAM, S. (2006). Learning Identity: The joint emergence of social identification and academic learning. New York:Cambridge University Press. 


\section{ANEXO}

\section{CONVENÇÕES DE TRANSCRIÇÃO}

Adaptação de Jefferson, Gail. (2004). Glossary of Transcript Symbols with an Introduction. In Gene H. Lerner, (ed.), Conversation Analysis: Studies from the First Generation, 13-31. Amsterdam:Benjamins.

Aspectos de produção de fala

\begin{tabular}{|c|c|c|}
\hline . & ponto final & entonação descendente \\
\hline ? & ponto de interrogação & entonação ascendente \\
\hline ， & virgula & entonação contínua \\
\hline$::::$ & dois pontos & alongamento de som \\
\hline$\uparrow$ & flecha para cima & som mais agudo \\
\hline$\downarrow$ & flecha para baixo & som mais grave \\
\hline- & hífen & interrupção abrupta da fala \\
\hline \#\#\#fala\#\# & Jogo-da-velha & tosse \\
\hline$\%$ fala \% / \%\%\%\% & Percentage & choro \\
\hline $\begin{aligned} \text { fala } & = \\
& =\text { fala }\end{aligned}$ & sinais de igual & $\begin{array}{l}\text { turnos de fala contíguos (sem } \\
\text { lapso de tempo interveniente) }\end{array}$ \\
\hline$\underline{\text { fala }}$ & sublinha & ênfase em som \\
\hline FALA & maiúscula & volume mais alto \\
\hline${ }^{\circ} \mathrm{fala}{ }^{\circ}$ & sinais de grau & volume mais baixo \\
\hline$>$ fala $<$ & $\begin{array}{l}\text { sinais de maior do que e me- } \\
\text { nor do que }\end{array}$ & fala acelerada \\
\hline$<$ fala $>$ & $\begin{array}{l}\text { sinais de menor do que e } \\
\text { maior do que }\end{array}$ & fala desacelerada \\
\hline $\begin{array}{l}\mathrm{fa}[\mathrm{la}] \\
\quad[\mathrm{fa}] \mathrm{la}\end{array}$ & colchetes & $\begin{array}{l}\text { fala sobreposta (mais de um } \\
\text { interlocutor falando ao mesmo } \\
\text { tempo) }\end{array}$ \\
\hline
\end{tabular}

Inspirações/expirações/risos

\begin{tabular}{|c|l|l|}
\hline .hhhhh & Série de h precedida de ponto & Inspiração audível \\
\hline hhhh & Série de h & Expiração audivel \\
\hline fa(hhh)la(hh) & Série de h entre parênteses & Riso ao falar \\
\hline$@ @ @ @ @ @ ~$ & Série de @ & risada \\
\hline
\end{tabular}




\section{Lapsos de tempo}

\begin{tabular}{|l|l|l|}
\hline$(3.5)$ & números entre parênteses & $\begin{array}{l}\text { medida de silêncio em segun- } \\
\text { dos e décimos de segundos) }\end{array}$ \\
\hline$()$. & ponto entre parênteses & $\begin{array}{l}\text { silêncio de menos de 2 déci- } \\
\text { mos de segundo }\end{array}$ \\
\hline
\end{tabular}

Formatação, comentários, dúvidas

\begin{tabular}{|c|l|l|}
\hline XXXXXX & série de $X$ & fala inaudível \\
\hline$($ fala $)$ & fala entre parênteses & dúvidas de transcrição \\
\hline$(($ comentários $))$ & parênteses duplos & comentários do transcritor \\
\hline
\end{tabular}

Recebido: 26/02/2016

Aceito: 21/03/2016 